\title{
Current and New Therapeutic Strategies for Relapsed and Refractory Multiple Myeloma: An Update
}

\author{
Inger S. Nijhof ${ }^{1} \cdot$ Niels W. C. J. van de Donk ${ }^{1} \cdot$ Sonja Zweegman $^{1}$ • \\ Henk M. Lokhorst ${ }^{1}$
}

Published online: 29 November 2017

(c) The Author(s) 2017. This article is an open access publication

\begin{abstract}
Although survival of multiple myeloma patients has at least doubled during recent years, most patients eventually relapse, and treatment at this stage may be particularly complex. At the time of relapse, the use of alternative drugs to those given upfront is current practice. However, many new options are currently available for the treatment of relapsed multiple myeloma, including recently approved drugs, such as the second- and third-generation proteasome inhibitors carfilzomib and ixazomib, the immunomodulatory agent pomalidomide, the monoclonal antibodies daratumumab and elotuzumab and the histone deacetylase inhibitor panobinostat, but also new targeted agents are under active investigation (e.g. signal transduction modulators, kinesin spindle protein inhibitors, and inhibitors of NF-kB, MAPK, AKT). We here describe a new paradigm for the treatment of relapsed multiple myeloma. The final goal should be finding a balance among efficacy, toxicity, and cost and, at the end of the road, achieving long-lasting control of the disease and eventually even cure in a subset of patients.
\end{abstract}

Inger S. Nijhof

i.nijhof@vumc.nl

1 Department of Hematology, VU University Medical Center, De Boelelaan 1117, 1081HV Amsterdam, The Netherlands

\section{Key Points}

Several new drugs have recently been approved for the treatment of patients with relapsed/refractory multiple myeloma

The therapeutic regimen of choice for patients with relapsed/refractory multiple myeloma depends on disease- and patient-related factors, as well as on type of prior treatment

\section{Introduction}

Over the past two decades, the median survival of patients with multiple myeloma (MM) has significantly improved, from 3 to 4 years to approximately 7-8 years [1], mainly due to the application of high-dose conventional therapy with autologous stem-cell transplantation (HDT-ASCT) as a routine procedure for transplant-eligible MM patients; significant improvements in supportive care strategies; and the introduction and wide-spread use of the immunomodulatory drugs (IMiDs) thalidomide and lenalidomide and the proteasome inhibitor (PI) bortezomib [2]. These novel agents nowadays represent the backbone of many current standard-of-care therapies for MM patients, both at diagnosis and in the relapse setting.

However, MM remains an incurable malignancy with most patients experiencing relapse and requiring additional therapy. In particular, the prognosis of MM patients who have received at least three prior lines of therapy, who have 
become double refractory to IMiDs (lenalidomide or pomalidomide) and PIs (bortezomib or carfilzomib) and who have been exposed to an alkylating agent, is very poor with an event-free survival and overall survival of only 5 and 13 months, respectively [3].

New insights into biology of the disease have resulted in the development of additional novel agents targeting specific pathways involved in tumor cell growth and survival. Due to their effectiveness and tolerability, some of these agents have received fast-track approval and have now moved to phase III and IV clinical studies. However, the optimal sequence of treatment and the optimal combinations both for frontline and relapsed and/or refractory myeloma is currently unknown. An important challenge will be the identification of these patient subsets that will benefit most from certain combinations of novel agents. Therefore, future studies should incorporate analysis of biomarker components that can predict the safety and effectiveness of new drugs, to select the appropriate patients to be treated with these new drugs.

This review provides an overview of the current evolving treatment strategies and challenges in the care of patients with relapsed and/or refractory multiple myeloma (RRMM).

\section{Clonal Evolution and Competition in Multiple Myeloma}

Keats et al. [4] found that approximately one-third of patients with MM have stable genomes, particularly those with low-risk hyper-diploid disease, potentially explaining their more favorable clinical outcomes. In another onethird of patients, genome changes over time were evident that are best explained by the existence of clonal heterogeneity at diagnosis. In the final one-third of patients, a pattern consistent with linear evolution was the dominant characteristic. The last two groups included the high-risk patients, suggesting that high-risk tumors are less stable and more prone to change with time [4]. Also, mutations involving individual genes are adding a further level of complexity to the concept of clonal evolution and heterogeneity. Additional studies have shown the importance of the evolution of adverse prognostic markers at relapse including the enrichment of MAPK gene mutations, adverse chromosomal prognostic markers, and biallelic inactivation of tumor suppressor genes [5-8].

These findings might have therapeutic implications. For instance, especially in the high-risk and relapsed and refractory setting, combination therapies, which confer anti-myeloma effects through different and complementary mechanisms, presumably targeting all coexisting disease sub-clones, will probably be particularly important, while sequential single-agent therapy might lead to preferentially eradicating the more indolent clone, allowing the more aggressive ones to expand. Another consideration might be that currently, retreatment of a patient with a regimen on which they have previously progressed is avoided because of the assumption of continued drug resistance. However, with intervening therapy, a sensitive sub-clone may have re-emerged, and retreatment might be effective again. Furthermore, certain mutations in some individual genes may have implications for targeted therapy. Nevertheless, the waves of different multiple myeloma clones evolving during the natural course of disease and the shifts in dominant and subdominant clones emerging during therapy and relapse are still chiefly an unraveled field and these findings require additional exploration before they may lead to personalized treatment care in MM [9].

\section{Prognostic Factors}

The course of MM is highly variable and depends on a variety of prognostic factors, including unfavorable highrisk cytogenetic abnormalities [del17p, t(4;14), ampl1q, $\mathrm{t}(14 ; 16), \mathrm{t}(14 ; 20)]$, a high-risk gene expression profile, high serum levels of lactodehydrogenase (LDH), a high International Staging System (ISS) stage (defined by the level of serum albumin and $\beta 2$-microglobulin), presence of extramedullary disease, presence of circulating plasma cells, or rapid progression or relapse during or after treatment $[10,11]$. Also, the proliferative rate of the malignant plasma cell is a prognostic determinant, which can be measured as the plasma cell labeling index [12] or by using $\mathrm{Ki}-67$ antigen expression [13].

Basic staging (albumin, $\beta 2$-microglobulin) does not necessarily represent the biologic heterogeneity at the time of diagnosis. This problem has recently been addressed by the revised ISS (R-ISS) [14]. The R-ISS risk stratification includes serum albumin and $\beta 2$-microglobulin for ISS staging, but also serum LDH and the cytogenetic abnormalities $\mathrm{t}(4 ; 14), \mathrm{t}(14 ; 16)$ and/or del17p to define high-risk, normal-risk and low-risk disease in newly diagnosed multiple myeloma. However, for MM patients in the relapse setting, the value of the prognostic score is yet unknown. Gene expression profiling (GEP) may identify patients with an unfavorable outcome, as has been shown with the EMC92 score, based on the prognostic signature from the 65/GMMG-HD4 clinical trial, and UAMS70 score, and UAMS80 score based on the 70- and 80-gene prognostic signatures by the UAMS researchers [15-17].

When combining 20 risk markers, including $\mathrm{t}(4 ; 14)$ and del17p (FISH), EMC92, UAMS70 and ISS, it was shown that the EMC92-ISS combination was the strongest predictor for overall survival. This combination identified four 
risk groups of which the median overall survival was only 24 months for the highest risk and was not reached for the lowest risk group. Also, extramedullary disease, which may be more easily detected nowadays by PET-CT scan [18], and circulating plasma cells are independent prognostic markers [19].

\section{Definitions of Relapsed Multiple Myeloma}

RRMM patients present a heterogeneous group of patients. The IMWG published definitions of relapsed MM, as well as refractory myeloma, and also treatment indications in 2006, 2009 and 2011 [20-22]. RRMM is regarded as a recurrence of the disease in patients treated to the point of maximal response and who then experience progression based on objective laboratory and radiologic criteria as depicted in Table 1.

Refractory to prior treatment indicates progressive disease on last prior treatment, best response of stable disease to last prior treatment, or progressive disease within 60 days of stopping prior therapy. There are two categories of refractory myeloma: "relapsed-and-refractory myeloma" and "primary refractory myeloma". Relapsed and refractory myeloma is defined as relapse in patients who must have achieved at least minimal response (MR), which either becomes non-responsive while on salvage therapy or progresses within 60 days of last treatment [20, 23]. Primary refractory myeloma is defined as disease that is nonresponsive; patients who have never achieved a MR or better with any therapy [23]. Double-refractory MM refers to disease refractory to both proteasome inhibitors and immunomodulatory drugs.

\section{Treatment Indication for Relapsed and/ or Refractory Multiple Myeloma}

In general, an indication for relapse treatment can be defined on clinical relapse and/or on significant M-protein (biochemical) relapse. Clinical relapse is defined as either the appearance or reappearance of one or more CRABcriteria (MM-associated symptoms, including hypercalcemia, renal failure, anemia, bone disease criteria), as well as increase in size of plasmacytomas $(>50 \%)$. Biochemical relapse is defined as doubling of the M-protein in two consecutive measurements separated by $\leq 2$ months; or an increase in the absolute levels of serum M-protein by $\geq 10 \mathrm{~g} / \mathrm{L}$, or urine M-protein increase by $\geq 500 \mathrm{mg} /$ $24 \mathrm{~h}$, or increase of the involved free light chain (FLC) level by $\geq 200 \mathrm{mg} / \mathrm{L}$ (plus an abnormal FLC ratio) in two consecutive measurements separated by $\leq 2$ months [22].

Treatment should be considered as well at the stage of biochemical relapse in the presence of high risk factors. These include aggressive disease at diagnosis, a short treatment-free interval with a suboptimal response to the previous treatment line, imminent risk for organ dysfunction such as previous light chain-induced renal impairment, or unfavorable cytogenetics as $t(4 ; 14)$ or del17p [24].

\section{Treatment Selection}

Since MM predominantly affects elderly patients (median age at diagnosis is 69 years, and almost one-third of patients is older than 75 years of age), the evaluation of patients' fitness is an important element when choosing therapy for the elderly MM patients. However, patients older than 65 years of age are highly heterogeneous with

Table 1 International Myeloma Working Group relapse criteria for multiple myeloma

Definition of relapsed multiple myeloma

Recurrence of the disease after prior response, defined on:

Objective laboratory criteria:

$\geq 25 \%$ increase of the serum M-protein (the absolute increase must be $\geq 5 \mathrm{~g} / \mathrm{L}$ )

or urine monoclonal protein (the absolute increase must be $\geq 200 \mathrm{mg} / 24 \mathrm{~h}$ )

or $\geq 25 \%$ difference between involved and uninvolved serum free light chains (the absolute increase must be $\geq 100 \mathrm{mg} / \mathrm{L}$ ) from its nadir, respectively,

Or objective radiologic criteria:

the definite development of new lytic bone lesions or soft tissue plasmacytomas

or definite increase in the size of existing bone lesions or soft tissue plasmacytomas increase, defined as a $\geq 50 \%$ increase and at least increase of $\geq 1 \mathrm{~cm}$ as measured serially by the sum of the products of the cross-diameters of the measurable lesion

Or the development of hypercalcemia that can be attributed solely to the plasma cell proliferative disorder.

In patients with non-secretory disease, relapse is defined as an increase of the bone marrow plasma cell percentage (the absolute rise in $\%$ must be $\geq 10 \%$ ). 
different levels of vulnerability. Based on this concept, the IMWG developed a frailty score including age, functional status, and comorbidities, in order to determine the frailty status of patients and the feasibility of treatment. According to this score, elderly patients are defined as fit, intermediate fit, and frail. This frailty score predicts mortality and the risk of toxicity in elderly myeloma patients [25]. The assessment of frailty may be helpful to choose the most appropriate therapeutic approach and to define treatment goals for each patient subgroup. Fit patients can be eligible for full-dose triplet-therapies, whereas unfit and frail patients may benefit from less-intensive triplet-regimens, doublet regimens or dose reductions according to expert-based local guidelines. Consistently, the goal of therapy is different in these groups: the goal of therapy for fit patients might be to achieve a complete remission and improve survival, while in frail patients it might be more important to improve and preserve the quality of life for as long as possible [25-27].

Other factors are important when selecting second-line therapy; for example, to consider high-risk features at the time of relapse and duration and depth of response to previous treatment. Furthermore, previous tolerability is an important consideration; factors like myelosuppression, neuropathy and thrombosis may influence the choice and dosing of therapy. In this respect, additional challenges arise towards the end stage of MM when many patients experience cytopenia due either to extensive bone marrow involvement or exhausted hematopoiesis due to prior therapies. Furthermore, treatment choices are also influenced by preferences and expectations of the patients and their families [28]. Figure 1 shows factors influencing the choice of therapy at relapse.

\section{New Treatment Options}

A better understanding of the biology of the disease has led to the development of new, effective agents that are able to overcome resistance to conventional therapies, and therefore prolong survival of MM patients. In this respect, several new anti-myeloma agents have shown activity, including next-generation IMiDs (pomalidomide) and proteasome inhibitors (carfilzomib, ixazomib), but also compounds with different mechanisms of action such as histone deacetylase inhibitors (HDACi), kinesin spindle protein inhibitors, and mTOR inhibitors [29].

Furthermore, the immune system is considered significantly compromised in MM patients. Multiple mechanisms of immune evasion by MM cells have been described, including reduced expression of tumor antigens and human leukocyte antigen (HLA) molecules by the malignant plasma cells [30-32], enhanced expression of inhibitory ligands, such as programmed cell death ligand 1 (PD-L1) by the plasma cells [33-36], and recruitment of regulatory $\mathrm{T}$ cells (Tregs) [37, 38] and myeloid-derived suppressor cells (MDSCs) [39-42], both of which can contribute to immune suppression. Therefore, also immunotherapy,

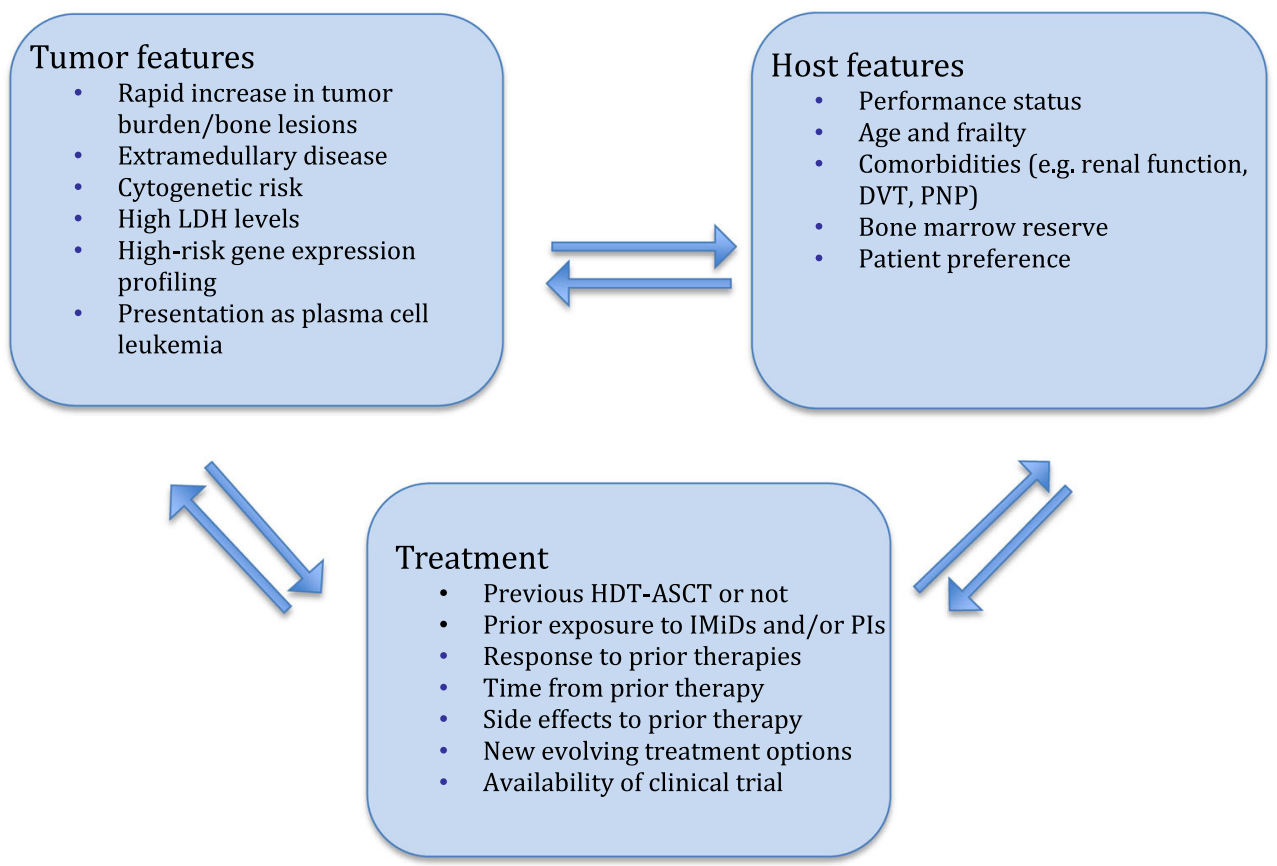

Fig. 1 Factors influencing choice of therapy at relapse. $L D H$ lactodehydrogenase, $D V T$ deep venous thrombosis, $P N P$ polyneuropathy, $H D T$ ASCT high-dose therapy-autologous stem cell transplantation, IMiDs immunomodulatory drugs, PIs proteasome inhibitors 
Table 2 Newer generations and classes of anti-myeloma drugs

\begin{tabular}{lc}
\hline Class & Mechanism of action \\
\hline $\begin{array}{l}\text { Immunomodulatory agents } \\
\text { Thalidomide }\end{array}$ & Direct antitumor activity, anti-angiogenic effects and indirect immunomodulatory effects \\
Lenalidomide & \\
Pomalidomide & Proteasome inhibition leads to accumulation of proteins within the myeloma cell resulting in growth arrest and cello \\
Proteasome inhibitors & death \\
Bortezomib & \\
Carfilzomib & \\
Ixazomib & \\
Marizomib & \\
Oprozomib & Increased acetylation of histone (and some non-histone) proteins, which regulates gene expression of tumor \\
Histone deacetylase inhibitors & suppressors, transcription factors and oncogenic proteins. Interference with protein degradation via the aggreso \\
Panobinostat & pathway, an alternative protein degradation process pathway to the proteasome pathway. Interference with the \\
Vorinostat & interaction of myeloma cells and the microenvironment \\
Romidepsin & Direct induction of apoptosis via activation or inhibition of target molecules. CDC, ADCC, ADCP. Immuno- \\
Monoclonal antibodies (mAbs) & modulation via altered immune subset activation. \\
Elotuzumab (anti-CS1/anti- & Other new developed mAbs are directed against cellular or non-cellular components of the microenvironment \\
SLAM7) & resulting in inhibition of angiogenesis, neutralization of growth factors, enhancing host antitumor immune \\
Daratumumab (anti-CD38) & responses, and modulation of mediators of bone disease \\
SAR650984 = isatuximab (anti- &
\end{tabular}

CD38)

MOR202 (anti-CD38)

Denosumab (anti-RANKL)

Siltuximab (anti-IL6)

IPH2101 (anti-KIR2DL1/2/3)

Checkpoint inhibitors

i.e. Nivolumab

Pembrolizumab

mTOR inhibitors

Everolimus

Temsirolimus

Akt inhibitors

Perifosine

MEK inhibitors

Selumetinib

Kinesin spindle protein inhibitors

Array-520

BH3 mimetics

ABT-199 (venetoclax)

ABT-263 (navitoclax)

Obatoclax mesylate

Vaccines

PVX-410

\section{CAR T}

i.e. against CD19, CD38, CS1, BCMA

Selective inhibitor of nuclear transport (SINE)

Checkpoint inhibitors target PD1 or PD-L1/PD-L2 whereby restoring T cell activity against tumor cells

Downstream mediator of the PI3 K/Akt pathway regulating translation of proteins involved in myeloma growth and survival

Prevention of cell cycle protein translation and inducement of G1 arrest

Decreased proliferation and survival of MM cells as well as inhibition of osteoclast bone resorption

To arrest cells in mitosis and to induce apoptosis due to degradation of the BCL2 family survival protein MCL-1

Binds to anti-apoptotic BCL2 family members, whereby inhibiting the binding of pro-apoptotic proteins

Selinexor

CDC complement-dependent cytotoxicity, ADCC antibody-dependent cellular cytotoxicity, ADCP antibody-dependent cellular phagocytosis, SLAM7 signaling lymphocyte-activating molecule-related receptor family $7, R A N K L$ receptor activator of nuclear factor kappa-B ligand, IL6 interleukin 6, $P D I$ programmed death 1, $P D-L 1$ programmed death-ligand 1, PD-L2 programmed death-ligand 2, mTOR mammalian target of rapamycin, $M M$ multiple myeloma, $C A R$ chimeric antigen receptor, $B C M A B$ cell maturation antigen 
aimed at engaging the immune system in the fight against malignant cells, is an attractive concept in MM treatment. A number of different strategies can be distinguished, such as monoclonal antibody ( $\mathrm{mAb}$ ) therapy, chimeric antigen receptor (CAR) T cells, checkpoint inhibition, and vaccination. Table 2 shows novel agents including next-generation novel drugs and immunotherapeutic developments in MM.

In the following section there will be a brief discussion of the most promising next-generation novel agents, novel drugs with different mechanisms of action, and immunebased approaches for the treatment of MM. Finally, treatment recommendations are given for first and subsequent relapsed myeloma.

\subsection{Next-Generation Novel Agents}

\subsubsection{IMiDs}

Pomalidomide is a next-generation oral immunomodulatory agent with strong direct anti-myeloma activity. It has potent immune-modulatory effects, as the activation of natural killer cells and inhibition of Tregs, and interferes with stroma cellsupport in the bone marrow [43]. The randomized phase III trial MM-003 compared pomalidomide and low-dose dexamethasone with high-dose dexamethasone in RRMM patients who have received prior bortezomib- and lenalidomide-based therapies. The median prior lines of treatment were 5 in both treatment arms. After a median follow-up of 10 months the overall response rate (ORR), defined as partial response or better, was $31 \%$ for patients treated with pomalidomide and low-dose dexamethasone vs $10 \%$ for patients treated with high-dose dexamethasone alone. In patients with at least partial response, median duration of response was 7.0 and 6.1 months, respectively. The pomalidomide and lowdose dexamethasone arm showed a significantly longer progression-free survival (PFS) of 4.0 vs 1.9 months, and overall survival (OS) of 12.7 vs 8.1 months [44]. The efficacy and favorable toxicity profile of this regimen has been confirmed in the STRATUS trial, a large phase III study evaluating pomalidomide plus low-dose dexamethasone in patients relapsed/refractory to bortezomib- and lenalidomide-based therapies. This study reported a median PFS of 4.6 months and a median OS of 12.9 months [45]. Pomalidomide has been approved by the US Food and Drug administration (FDA) and European Medicines Agency (EMA) in 2013 for its use alone or in combination with dexamethasone in RRMM patients who have received at least two prior lines of treatment including lenalidomide and bortezomib.

Interestingly, data from the Intergroupe Francophone du Myélome (IFM) study indicate that pomalidomide combined with dexamethasone is also active in adverse cytogenetic patients with early RRMM, particularly in patients with del(17p) [46].

Several clinical trials evaluated the role of pomalidomide-based combination regimens in RRMM patients. The addition of cyclophosphamide to pomalidomide and dexamethasone has been found to increase both response rates and PFS; pomalidomide-cyclophosphamide-prednisone (PCP) in relapsed and/or refractory pomalidomide-naive MM patients, treated with a median of 3 prior lines of treatment, showed an ORR of $51 \%$ and a median PFS of 10.4 months [47]. Furthermore, a recent randomized phase II trial compared the combination pomalidomide-cyclophosphamide-dexamethasone with pomalidomide-dexamethasone in heavily pretreated pomalidomide-naive RRMM patients with a median of 4 prior treatment lines, and demonstrated an ORR of 64.7 vs $38.9 \%$ and a PFS of 9.5 vs 4.4 months, respectively [48].

The combination of the IMiD lenalidomide with cyclophosphamide and prednisone (REP-therapy; Revlimid, Endoxan, Prednisone) has recently been evaluated in a prospective phase I/II clinical trial. Importantly, all patients in this trial had lenalidomide-refractory MM. The maximal tolerated dose (MTD) was defined as $25 \mathrm{mg}$ lenalidomide (days 1-21/28 days cycle), combined with continuous cyclophosphamide $(50 \mathrm{mg} /$ day $)$ and prednisone ( $20 \mathrm{mg} /$ day). At the MTD, the ORR was $67 \%$ with a median PFS and OS of 12.1 and 29.0 months, respectively [49]. In this study, lenalidomide plus cyclophosphamide and prednisone had a generally favorable tolerability profile, with the most frequent grade 3-5 adverse events being myelosuppression [neutropenia (22\%) and thrombocytopenia (22\%)], and infections (21\%), consistent with the observed toxicities in MM patients treated with lenalidomide-dexamethasone [49-51].

Furthermore, encouraging results were shown from the phase I/II trial combining carfilzomib, pomalidomide and dexamethasone in RRMM with an ORR of $58 \%$. With a median follow-up period of 10 months, the median PFS was 9.5 months and the median OS was not yet reached. The ORR for the high-risk patients was 44\% [52].

Altogether, combination strategies with IMiDs in the RRMM treatment setting have been shown to be effective and tolerable. The most frequent pomalidomide-related adverse events are myelosuppression, fatigue, and infections. Peripheral neuropathy, rash, gastrointestinal complaints, and muscle cramps are rare described adverse events. Provided that thrombosis prophylaxis is given, thromboembolic events are also rare.

\subsubsection{Proteasome Inhibitors}

Carfilzomib is a second-generation proteasome inhibitor that irreversibly and selectively inhibits the chymotrypsin- 
Table 3 Selected clinical phase III combination studies with lenalidomide in the RRMM setting (1-3 prior lines, in lenalidomide-naive or lenalidomide-sensitive MM patients)

\begin{tabular}{|c|c|c|c|c|c|c|c|c|}
\hline Study & $N$ & $\begin{array}{l}\text { Median lines of } \\
\text { prior treatment }\end{array}$ & $\begin{array}{l}\text { ORR } \\
(\%)\end{array}$ & Treatment & $\begin{array}{l}\text { Median } \\
\text { PFS (m) }\end{array}$ & $\begin{array}{l}\text { PFS HR } \\
(95 \% \text { CI })\end{array}$ & Median OS (m) & $\begin{array}{l}\text { OS HR } \\
(95 \% \mathrm{CI})\end{array}$ \\
\hline Pollux [82] & 569 & $1(1-11)$ & 93 vs 76 & DRd vs Rd & NE vs 18.4 & $\begin{array}{l}0.37 \\
\quad(0.27-0.52)\end{array}$ & NE vs NE & $\begin{array}{l}0.64 \\
\quad(0.40-1.01)\end{array}$ \\
\hline Aspire [57] & 792 & $2(1-3)$ & 87 vs 67 & KRd vs Rd & 26.3 vs 17.6 & $\begin{array}{l}0.69 \\
\quad(0.57-0.83) \\
p=0.0001\end{array}$ & $2-y r: 73$ vs $65 \%$ & $\begin{array}{l}0.79 \\
\quad(0.63-0.99) \\
p=0.04\end{array}$ \\
\hline Eloquent2 [72, 124] & 646 & $2(1-4)$ & 79 vs 66 & ERd vs Rd & 19.4 vs 14.9 & $\begin{array}{l}0.70 \\
\quad(0.57-0.85) \\
p<0.001\end{array}$ & 43.7 vs 39.6 & $\begin{array}{l}0.77 \\
\quad(0.61-0.97) \\
p=0.257\end{array}$ \\
\hline $\begin{array}{l}\text { Tourmaline- MM1 } \\
\text { [61] }\end{array}$ & 722 & $2(1-3)$ & 78 vs 72 & IRd vs Rd & 20.6 vs 14.7 & $\begin{array}{l}0.74 \\
\quad(0.59-0.94) \\
p=0.012\end{array}$ & NE vs NE & $\mathrm{NE}$ \\
\hline
\end{tabular}

$R R M M$ relapsed and/or refractory multiple myeloma, $N$ number, $O R R$ overall response rate, $P F S$ progression-free survival, $m$ months, $H R$ hazard ratio, $C I$ confidence interval, $O S$ overall survival, $D R d$ daratumumab-lenalidomide-daratumumab, $R D$ lenalidomide-dexamethasone, $K R d$ carfilzomib-lenalidomide-dexamethasone, ERd elotuzumab-lenalidomide-dexamethasone, IRd ixazomib-lenalidomide-dexamethasone, $v s$ versus, $N E$ non-evaluable

like site of the proteasome. Carfilzomib has been approved by the FDA in 2012 and the EMA in 2015 as a single agent for the treatment of patients with relapsed and refractory myeloma previously treated with lenalidomide and bortezomib.

As monotherapy in RRMM patients, carfilzomib induced an ORR of $23.7 \%$ with a median duration of response of 7.8 months and a median OS of 15.6 months [53]. In the phase III FOCUS trial, 315 patients with RRMM were randomized between single-agent carfilzomib vs low-dose steroids with or without continuous low-dose oral cyclophosphamide. The control arm received $30 \mathrm{mg}$ oral prednisone or $6 \mathrm{mg}$ oral dexamethasone. The addition of $50 \mathrm{mg}$ oral cyclophosphamide to the control group was optional; however, $94.8 \%$ of patients received this additional therapy. The OS in the carfilzomib group was 10.2 months, compared to 10.0 months $(p=0.42)$ in the control group. There was a slight difference in favor of carfilzomib in ORR (19.1\% vs $11.1 \%, p=0.03)$; however, this was not translated into an increase of PFS [3.7 and 3.3 months for the carfilzomib and control group, respectively $(p=0.25)]$. The failure of the study to show differences with the control arm was probably due to the high efficacy of additional cyclophosphamide in the control group. The addition of cyclophosphamide to novel agents, for instance thalidomide, bortezomib, and lenalidomide, has shown significantly increased response rates [54-56] even in the setting of the addition of cyclophosphamide to lenalidomide in lenalidomide-refractory MM [49].

In the ASPIRE trial, relapsed MM patients were randomized between carfilzomib-lenalidomide-dexamethasone and lenalidomide-dexamethasone, which resulted in an ORR of 87 vs $67 \%$ and in a PFS of 26.3 vs 17.6 months respectively [57] (Table 3).

The ENDEAVOR study compared carfilzomib-dexamethasone with bortezomib-dexamethasone in RRMM patients. The ORR of carfilzomib-dexamethasone was superior with $77 \%$ compared to $63 \%$ for bortezomib-dexamethasone in this study. Carfilzomib-dexamethasone also showed a longer PFS (18.7 vs 9.4 months) [58] (Table 4). Data from these trials have led to the approval of these triplet and doublet combination treatments with carfilzomib for MM patients who have received at least one previous line of therapy.

Carfilzomib has a favorable side-effect profile compared to bortezomib, especially the low incidence of treatmentemerging peripheral neuropathy, and after prolonged treatment, makes it an attractive agent to incorporate in treatment protocols. On the other hand, a combined safety analysis of four phase II trials of single-agent carfilzomib reported an overall cardiac-related adverse events rate of any grade of $22 \%$, especially dyspnea, hypertension, and heart failure [59]. These cardiac adverse events were predominantly grade 1 and 2 adverse events and mostly transient, and resolved in most patients without dose adjustments [59]. Carfilzomib-associated cardiotoxicity $\geq$ grade 3 cardiac failure occurred in $4.8 \%$ of patients; most of these patients had a history of cardiovascular events $(74 \%)$ or had baseline cardiac risk factors $(70 \%)$ [59]. Tight blood pressure control and baseline cardiac assessment has been described to lower the cardiac adverse event rate. Further studies to better understand the biological basis of carfilzomib-related cardiotoxicity to develop guidelines for appropriate prevention and management are ongoing [60]. 
Table 4 Selected clinical phase III combination studies with PIs bortezomib in the RRMM setting (1-3 prior lines, in bortezomib-naive or bortezomib-sensitive MM patients)

\begin{tabular}{|c|c|c|c|c|c|c|c|c|}
\hline Study & $N$ & $\begin{array}{l}\text { Median lines of } \\
\text { prior treat-ment }\end{array}$ & ORR $(\%)$ & Treatment & $\begin{array}{l}\text { Median } \\
\text { PFS (m) }\end{array}$ & PFS HR (95\% CI) & Median OS (m) & $\begin{array}{l}\text { OS HR } \\
(95 \% \mathrm{CI})\end{array}$ \\
\hline Castor [86] & 498 & $2(1-10)$ & 83 vs 63 & DVd vs Vd & NE vs 7.2 & $\begin{array}{l}0.39(0.28-0.53) \\
p<0.0001\end{array}$ & NE vs NE & $0.77(0.47-1.26)$ \\
\hline Endeavor [58] & 929 & $2(1-2)$ & 77 vs 63 & Kd vs Vd & 18.7 vs 9.4 & $\begin{array}{l}0.53(0.44-0.65) \\
p<0.0001\end{array}$ & NE vs 24.3 & $\begin{array}{l}0.79(0.58-1.08) \\
p=0.13\end{array}$ \\
\hline Panorama-1 $[67,135]$ & 768 & $1(1-3)$ & 61 vs 57 & PVd vs Vd & 12.0 vs 8.1 & $\begin{array}{l}0.63(0.52-0.76) \\
p<0.0001\end{array}$ & 40.3 vs 35.8 & $\begin{array}{l}0.94(0.69-1.10) \\
p=0.54\end{array}$ \\
\hline
\end{tabular}

$R R M M$ relapsed and/or refractory multiple myeloma, $N$ number, $O R R$ overall response rate, $P F S$ progression-free survival, $m$ months, $H R$ hazard ratio, $C I$ confidence interval, $O S$ overall survival, $D V d$ daratumumab-bortezomib-daratumumab, $V d$ bortezomib-dexamethasone, $K d$ carfilzomibdexamethasone, $P V d$ panobinostat-bortezomib-dexamethasone, $v s$ versus, $N E$ non-evaluable

Ixazomib, the first oral proteasome inhibitor, was tested in the TOURMALINE MM phase III study, for patients with relapsed, refractory, or both relapsed and refractory MM, who had received one to three prior therapies and were not refractory to prior lenalidomide therapy or proteasome inhibitor-based therapy. This study demonstrated that the combination of ixazomib-lenalidomide-dexamethasone was superior to lenalidomide and dexamethasone with an ORR of $78 \%$ compared to $72 \%$, and a median PFS of 20.6 months compared to 14.7 months in the control group [61] (Table 3). Ixazomib is associated with a favorable toxicity profile with a lower risk of polyneuropathy in comparison to bortezomib. However, a higher rate of gastrointestinal adverse events has been reported. Ixazomib-lenalidomide-dexamethasone is currently tested in a large phase III study in newly diagnosed MM patients, whereas two other phase-III studies are testing ixazomib as maintenance therapy after autologous stem-cell transplantation (ASCT) in younger MM patients and after standard induction therapy in elderly patients.

Marizomib and oprozomib are new-generation proteasome inhibitors currently tested in phase I-II clinical trials. Marizomib inhibits all three proteolytic sites of the enzyme, showing a greater activity on myeloma cells compared to bortezomib in preclinical models. Oprozomib is structurally related to carfilzomib, with the advantage of oral administration. Of note, encouraging activity of marizomib has been reported in patients with involvement of MM in their central nervous system, which has normally limited therapeutic options [62].

\subsection{Novel Drugs with Different Mechanisms of Action}

\subsubsection{Histone Deacetylase Inhibitors}

Controlling the coiling and uncoiling of DNA around histones is essential for gene expression. Histone acetyl transferases acetylate, the lysine residues in core histones, resulting in less compact and transcriptionally more active chromatin. Conversely, histone deacetylases (HDACs) remove the acetyl groups from the lysine residues leading to the formation of a condensed and transcriptionally silenced chromatin. Inhibition of this process results in increased gene expression and in cell cycle arrest, differentiation and/or apoptosis. Histone deacetylase inhibitors (HDACi) are a novel class of agents that target these HDAC enzymes, which are involved in the unfolded protein response pathways and in the epigenetic regulation of gene expression, promoting cell proliferation and cell death. Overexpression of HDACs has been reported in several cancers, including MM [63]. HDACi exert their antitumor activity via the inhibition of these HDACs that leads to increased acetylation of histone (and some nonhistone) proteins, which regulates the expression of tumor suppressors, transcription factors and oncogenic proteins. Increased histone acetylation by panobinostat also blocks the aggresome pathway, an alternative protein degradation process that may enable MM cells to develop resistance to proteasome inhibitors [64].

Despite demonstration of promising preclinical activity, monotherapy with the pan-HDACi vorinostat failed to provide any clinical benefit, while its use in combination with bortezomib resulted in a relevant increase in toxicity $[65,66]$. More promising clinical results have been reported with the pan-HDACi panobinostat that has been granted fast-track approval by the FDA in combination with bortezomib and dexamethasone for the treatment of RRMM patients who have received at least two prior regimens, including bortezomib and an IMiD. This fasttrack approval is based on increased PFS for the triple combination of panobinostat with bortezomib and dexamethasone compared to bortezomib and dexamethasone alone, demonstrated in a phase III clinical study [67] (Table 4). In this study, panobinostat plus bortezomib and dexamethasone had a generally manageable tolerability 
profile, with the most frequent grade 3-4 adverse events being myelosuppression, diarrhea, asthenia or fatigue, peripheral neuropathy and pneumonia [67]. The simultaneous blockade of the aggresome and ubiquitin-proteasome pathway by panobinostat and bortezomib may explain their synergistic antitumor activity when used in combination.

\subsubsection{Monoclonal Antibody Therapy}

Monoclonal antibodies (mAbs) are already a widely used treatment modality in hematology, with rituximab being the most prominent example. This agent was approved for the treatment of lymphoma by the FDA in 1997 and by the EMA in 1998 [68], and is now considered a standard therapy in lymphoma that has had a major impact on survival [69]. Until recently, no appropriate mAbs were available for MM. However, a large series of monoclonal antibodies targeting different epitopes on myeloma cells or immune and stromal cells are emerging with various candidates having been FDA- and EMA-approved now, with others in late-stage clinical development [70]. The targets for monoclonal antibody development in MM have been either surface proteins or cytokines considered to be relevant for disease biology. Until now, two monoclonal antibodies, elotuzumab and daratumumab, have been approved for the treatment of patients with relapsed MM.

\subsubsection{Elotuzumab Elotuzumab is a humanized mono-} clonal antibody targeting CS1, a cell surface glycoprotein and member of the signaling lymphocyte-activating molecule-related receptor family 7 (SLAM7), highly expressed on virtually all MM cells, with lower expression on natural killer cells and little or no expression in normal tissue [71]. The role of CS1 in the pathogenesis of MM is still unclear. Elotuzumab works mainly via antibody-dependent cellular cytotoxicity (ADCC). Elotuzumab as a single agent has shown no or little activity with stable disease in approximately $25 \%$ of patients and no objective responses. However, combination therapy of elotuzumab with lenalidomide and dexamethasone has revealed a favorable safety profile and encouraging response rates with at least PR in $79 \%$ vs $66 \%$ of patients treated with lenalidomide and dexamethasone in relapsed MM patients (Eloquent-2 study) [72]. The median PFS was 19.4 months for the patients treated with elotuzumab-lenalidomidedexamethasone vs 14.9 months for the patients treated with lenalidomide-dexamethasone [HR $0.70(0.57-0.85)]$, while the OS was 43.7 vs 39.6 months, respectively [HR 0.77 (0.61-0.97)] [72] (Table 3).

7.2.2.2 Daratumumab Another $\mathrm{mAb}$ that recently became available for the treatment of MM patients is daratumumab, a fully human immunoglobulin G1 kappa

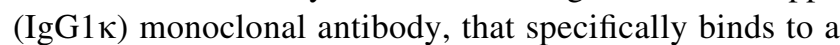
unique epitope present on the CD38 molecule. CD38 is a multifunctional cell surface protein that possesses receptor as well as enzyme functions. As a transmembrane receptor and through its binding to CD31, CD38 is involved in leukocyte adhesion, activation and proliferation [73]. In addition to this receptor function, CD38 acts as an ectoenzyme; CD38 is a cyclic ADP ribose hydrolase that regulates intracellular $\mathrm{Ca}^{2+}$ influx, leading to the activation of several signaling pathways, eventually leading to the efflux of adenosine, which has an immunosuppressive effect on cytotoxic $\mathrm{T}$ cells [73]. Virtually all MM cells express high levels of CD38 on their cell surface [74]. However, CD38 is also expressed, although to lower levels, on lymphoid and myeloid cells as well as on several non-hematopoietic tissues (i.e. pancreas, brain, and muscle) [75]. Daratumumab binds CD38 with high affinity and induces myeloma cell death via complement-dependent cytotoxicity (CDC), ADCC, antibody-dependent cellular phagocytosis (ADCP), via CD38 signaling pathway modulation and via the induction of tumor cell apoptosis via $\mathrm{FC} \gamma \mathrm{R}$ crosslinking [76-78]. Daratumumab also induces indirect antitumor activity through the elimination of CD38-positive immunosuppressive cells (Tregs, Bregs, and MDSCs), leading to enhanced CD8 $+\mathrm{T}$ cell effector functions [79]. Interestingly, similar activity on immunosuppressive cells has also been described with isatuximab, another CD38-targeted monoclonal antibody [80].

Daratumumab has been evaluated as a single agent in two clinical studies in heavily pretreated RRMM patients. A pooled analysis of these studies has shown that daratumumab monotherapy is well tolerated and that in the $16 \mathrm{mg} / \mathrm{kg}$ cohort at least a partial response can be achieved in $31 \%$ of the patients with a median PFS and OS of 4.0 and 20.1 months, respectively [81]. As a result, the FDA and EMA approved daratumumab monotherapy for MM patients who have received three or more prior lines of therapy, including a PI and an IMiD, or who are double refractory to a PI and an IMiD.

Also for daratumumab, combination therapies engage stronger effects; combination therapy of daratumumab with lenalidomide and dexamethasone has revealed at least PR in $93 \%$ (including $43 \% \mathrm{CR} / \mathrm{sCR}$ ) vs $76 \%$ (including $19 \%$ $\mathrm{CR} / \mathrm{sCR}$ ) of patients treated with lenalidomide and dexamethasone in a phase III randomized clinical trial in relapsed MM patients (Pollux study) [82, 83]. Importantly, minimal residual disease (MRD) negativity was more common in daratumumab-lenalidomide-dexamethasone (DRd) patients than in lenalidomide-dexamethasone (Rd) patients (22.4 vs $4.6 \%$ MRD negativity, respectively, defined with next-generation sequencing with a sensitivity 
threshold of $10^{-5}$ ) [84]. Median PFS was not reached for the patients treated with DRd vs 18.4 months for the patients treated with $\mathrm{Rd}$, respectively [HR 0.37 (0.27-0.52)]. Moreover, patients with high-risk cytogenetics ( $n=33$ in each treatment group) had longer PFS with DRd (median, not reached vs 8.3 months; HR, 0.30; $p=0.0019$ ). Median OS was not reached in either group with a hazard ratio (HR) of $0.64(0.40-1.01)$ [82, 83] (Table 3). The phase III randomized Castor trial showed advantage of the addition of daratumumab to bortezomib/ dexamethasone with at least PR in $83 \%$ (including 19\% $\mathrm{CR} / \mathrm{sCR}$ ) for the patients treated with the triple combination vs $63 \%$ (including $9 \% \mathrm{CR} / \mathrm{sCR}$ ) of patients treated with bortezomib and dexamethasone in relapsed $\mathrm{MM}$ patients [85, 86]. Here, MRD negativity was more common in daratumumab-bortezomib-dexamethasone (DVd) patients than in bortezomib-dexamethasone patients (7.2 vs 1.6\% MRD negativity, respectively) [84]. The median PFS was not reached for the patients treated with daratumumabbortezomib-dexamethasone vs 7.2 months for the patients treated with bortezomib-dexamethasone [HR 0.39 (0.28-0.53)], while the median OS was not reached in both groups with a HR of $0.77(0.47-1.26)$ [85, 86] (Table 4). Due to the valuable safety profile and encouraging efficacy data in these trials in the RRMM treatment setting, daratumumab is currently tested in extensive phase III randomized trials in which daratumumab is added to upfront treatment schemes for transplant-eligible as well as for transplant-ineligible patients. When proven effective, mAbs may become a standard part of upfront therapy. In line with the development of other monoclonal antibodies (i.e. rituximab), a subcutaneous administration of daratumumab is currently evaluated with the objectives to limit the time of infusion and the rate of infusion-related reactions, the most important side effect of daratumumab.

Other monoclonal antibodies targeting CD38 are currently being evaluated in MM. Isatuximab is an IgG chimeric antibody that has already demonstrated clinical activity alone and in combination strategies in relapsed MM patients [87, 88]. MOR202 is another CD38 IgG human antibody that has shown promising activity alone and in combination with pomalidomide and lenalidomide in relapsed MM patients [89].

\subsubsection{Checkpoint Inhibitors}

Programmed cell death-1 (PD-1, CD279) is a member of the CD28 receptor family. Its ligands, either PD-L1 (CD274) or PD-L2 (CD273), play a fundamental role in tumor immune escape by inhibiting immune effector functions. PD-1 expression is induced on antigen activated $\mathrm{T}$ cells and exhausted T cells and B cells; PD-L1 is mainly expressed by antigen-presenting cells (APC) and various non- hematopoietic cells; and PD-L2 is found on hematopoietic cells, including dendritic cells and macrophages. In cancer initiation and development, tumor cells suppress immune surveillance by using PD-L1 ligand to engage the PD1 receptor on $\mathrm{T}$ cells and inhibit $\mathrm{T}$ cell activation [90]. Checkpoint inhibitors targeting PD1 or PD-L1 or PD-L2 therefore restore $\mathrm{T}$ cell activity against tumor cells and have emerged as a vital new therapeutic strategy. Notably, increased PD-L1 expression has been shown in multiple myeloma cells compared with healthy donor plasma cells [33, 36, 91-93] and increased PD-1 expression has been demonstrated on CD4+ T cells in multiple myeloma [33, 92-94]. As a single agent, nivolumab, a PD-1 inhibitor, had minimal activity in relapsed MM, with a SD rate of $67 \%$ in a phase I trial; partial responses or better were not seen [95]. Although immune checkpoint inhibition with PD-1 inhibitors had limited efficacy when the inhibitors are used as single agents, it has led to promising results when the inhibitors are combined with immunomodulatory drugs such as lenalidomide and pomalidomide $[96,97]$. A recent trial with pembrolizumab and lenalidomide demonstrated an ORR of $74 \%$ in patients with two or more prior lines of treatment [97]. A trial with pomalidomide and pembrolizumab showed an ORR of $60 \%$, while these patients were heavily pre-treated, with a median of three prior lines of treatment and, importantly, $73 \%$ of these patients were refractory to both immunomodulatory drugs and proteasome inhibitors. PFS was 17.4 months, and OS not yet reached [96]. However, recently the FDA placed partial and full clinical holds on trials with PD-(L)1 inhibitors in combination with immunomodulatory agents in patients with myeloma, chronic lymphatic leukemia, or lymphoma due to possible safety concerns. Further in-depth analyses are currently performed, meanwhile these trials are not enrolling any new patients.

\subsubsection{Vaccines}

Vaccination against cancer-specific antigens presents a promising strategy to modulate patient antitumor immune response, particularly in the setting of early-stage disease (i.e. in smoldering $\mathrm{MM}$ ) or in the setting of minimal residual disease. The vaccine PVX-410 consists of a cocktail of HLA-A2-specific peptides derived from X-box binding protein 1, CD138, and SLAMF-7 MM antigens, which can trigger HLA-restricted expansion and activation of MM-specific T cells [98]. Vaccination therapy combined with IMiDs and/or with anti-PD-1 mAbs might further enhance MM-specific immune responses.

\subsubsection{Chimeric Antigen Receptor T Cells}

Like monoclonal antibodies, chimeric antigen receptor (CAR) $\mathrm{T}$ cells are targeted therapies directed against a cellsurface antigen on malignant cells. However, CAR T cells 
are potentially more potent than mAbs and can establish long-lived immunity against the target antigen after a single infusion. CARs are engineered receptors that artificially confer specificity of $\mathrm{T}$ lymphocytes for native cell-surface antigens [99].

For MM, CAR-T cells directed against e.g. CD38, CS1, B cell maturation antigen (BCMA), CD138, kappa light chain, NKG2D and CD44v6 have demonstrated preclinical anti-MM activity. Phase I clinical trials with CAR T cells, directed against BCMA, for example, are currently recruiting MM patients [100] and have shown promising tumor cell reductions, even in high-risk and RRMM $[101,102]$.

\section{Targeted Therapy in Multiple Myeloma}

Interaction of $\mathrm{MM}$ cells with bone marrow stromal cells (BMSCs) induces activation of MEK/ERK, JAK2/STAT3, and PI3 K/Akt signaling pathways, resulting in proliferation, survival, drug resistance, and migration of MM cells [103-105]. Various new anti-myeloma drugs interfere in these interactions and are currently being investigated in clinical trials, which includes RAF-inhibitors (sorafenib), BRAF inhibitors (vemurafenib), kinesin spindle protein inhibitors (ARRY-520), Akt inhibitors (perifosine), and BH3 mimetics (venetoclax) (Table 2).

Sorafenib is a drug targeting the RAS-RAF-MEK-ERK pathway and inhibiting the actions of the vascular endothelial growth factor (VEGF). Since the RAS-RAFMEK-ERK pathway is often mutated in MM, leading to uncontrolled growth of tumor cells, and VEGF is stimulating bone marrow neovascularization, sorafenib is a drug offering the potential for targeting two important pathogenic mechanisms involved in MM [106]. However, sorafenib showed only minimal anti-myeloma activity as a single agent in RRMM patients with beneficial activity in 2 out of 11 heavily pretreated myeloma patients in one study [107], and no objective responses observed in another study with 14 evaluable MM patients [108].

Approximately 3-5\% of MM patients have mutations in BRAF. Inhibitors like vemurafenib are highly active in BRAF-mutated patients, but the duration of response is usually limited due to the development of alternative activation pathways as increased expression of PDGFR or activations of NRAS mutations. Vemurafenib resulted in significant tumor reduction in patients with BRAF V600E mutations [109].

Filanesib (ARRY-520) is a kinesin spindle protein inhibitor, which arrests cells in mitosis and induces apoptosis due to degradation of the BCL2 family survival protein MCL-1. A phase II study with filanesib with and without dexamethasone showed an ORR of $22 \%$ with a median duration of response between 5.1 and 8.6 months [110].

The PI3 K/Akt/mTOR pathway is aberrantly active in $\mathrm{MM}$ and contributes to cell growth, proliferation, and survival. Akt is a nodal regulator of cellular survival pathways and might be an attractive target in cancer therapy. Many inhibitors of Akt are being developed. Perifosine is an oral Akt inhibitor inhibiting the nuclear translocation of NF- $\kappa \mathrm{B}$ [111]. The intrinsic apoptosis pathway in $\mathrm{MM}$ cells is regulated by a balance between anti-apoptotic (e.g. BCL-2, BCL-XL, MCL-1) and proapoptotic (e.g. BAX, BAK, NOXA) proteins [112-114]. Venetoclax is a new oral selective BCL-2 inhibitor that promotes apoptosis in MM cell lines and primary samples, particularly in myeloma cells with $\mathrm{t}(11 ; 14)$, which express high levels of BCL-2 relative to BCL-XL and MCL-1 [115]. Translocation $(11 ; 14)$ is seen in $15-20 \%$ of patients with MM [116]. Recently, data of an open-label phase I study in RRMM patients, with a median of 5 prior therapies, showed an ORR of $21 \%$. Confirming preclinical data, most responses [12 out of 14 responses (86\%)] were reported in patients with $\mathrm{t}(11 ; 14)$; the ORR was $40 \%$ (12 of 30 patients) in patients with $\mathrm{t}(11 ; 14)$, while only $6 \%$ of the patients without $\mathrm{t}(11 ; 14)$ responded to treatment with venetoclax [116]. Responses in the $t(11 ; 14)$ group were durable, with a median duration of response of 9.7 months [116]. Moreover, venetoclax in combination with bortezomib and dexamethasone achieved remarkable activity in a phase Ib study in RRMM patients with a median of 3 prior therapies. Specifically, the combination therapy was well tolerated, with an ORR of $67 \%$ (90\% in patients not refractory to bortezomib; and $31 \%$ in patients who were refractory to bortezomib); with the MTD not reached. The clinical benefit was higher in patients with fewer lines of therapy, not refractory to bortezomib, and those with high BCL-2 expression [117]. A phase III study for RRMM patients with 1-3 prior lines of therapy comparing venetoclax plus bortezomib and dexamethasone vs bortezomib and dexamethasone is ongoing. A common adverse side effect in $M M$ is gastrointestinal toxicity. Serious adverse effects included pneumonia (8\%) and sepsis (5\%). Tumor lysis syndrome, a significant problem in chronic lymphocytic leukemia (CLL) patients, has not been observed.

Selinexor is a first-in-class selective inhibitor of nuclear export (SINE) and binds and inhibits protein exportin-1 (XPO-1), which is the nuclear exporter for the majority of tumor suppressor proteins. Selinexor induces retention and activation of the tumor-suppressor proteins NF-kB, p53 and FOXO; furthermore, selinexor induces the glucocorticoid receptor in the presence of steroids. Also, it suppresses oncoprotein expression as Myc and cyclin D. Promising preclinical data [118] have led to phase I/II clinical trials. A phase IIb open-label, single-arm Selinexor Treatment of 
Refractory Myeloma (STORM) study evaluated selinexor in combination with low-dose dexamethasone in relapsed and refractory MM patients after a median of 7 prior therapies. Preliminary results show an ORR of $21 \%$ (with a similar response rate in patients with high-risk MM); a median duration of response of 5 months, a median PFS of 2.3 months, and a median OS of 9.3 months. Primary toxicities included thrombocytopenia, nausea, anorexia, fatigue, and anemia; aggressive supportive care was required [119]. The combination of selinexor with bortezomib/dexamethasone, selinexor plus lenalidomide/dexamethasone and selinexor plus daratumumab/ dexamethasone is under evaluation. Preliminary data on the selinexor-bortezomib combination show an ORR of $77 \%$ [120].

\section{Treatment Recommendations}

\subsection{Treatment at First Relapse}

Three general approaches to the management of symptomatic disease relapse following initial ASCT may be considered: (i) reinduction therapy followed by salvage HDT-ASCT for transplant-eligible patients, (ii) reinduction therapy with double or triple regimens using combinations of novel therapies for relapsed MM until development of progressive disease, and (iii) participation in clinical trials to evaluate any of the prior and new therapeutic options. Currently, only limited comparative data are available to support one approach over another [121-123].

At the time of relapse when second-line treatment is necessary, it is currently advised that patients not previously treated with a novel agent, should be treated with a proteasome inhibitor-based regimen, or an IMiD-based regimen, or a combination of both. Patients previously treated with an IMiD-based regimen should preferably be treated with a proteasome inhibitor-containing regimen at relapse if there is IMiD-refractory disease. Patients initially treated with a proteasome inhibitor-containing regimen, should preferably be treated with an IMiD-containing regimen as second-line treatment.

In general, doublet or triplet regimens are preferred above single agents for inducing optimal effects. Recently, different phase III clinical trials with novel-agent based triplet combinations demonstrated superior response rates and prolonged disease control when compared with twodrug regimens in several randomized clinical trials, without adding any relevant additional toxicity $[57,58,61,67,72,82,86,124]$. These triplet therapies are likely to play a key role in overcoming drug resistance and hold promise to further improve long-term outcomes of relapsed MM patients. Table 3 shows phase III clinical trials with triplet therapies with lenalidomide; Table 4 shows phase III clinical trials with combination therapies with bortezomib. Currently, there are many different options in the relapse setting and there are no phase III clinical trials that compare these options, head-to-head. Therefore, it is currently impossible to define the optimal sequence. Choice of therapy has to be adapted on an individual basis according to patient's characteristics, tumor features and prior treatment.

Although triplet therapies do not completely abrogate poor prognosis associated with high-risk cytogenetics, compared to doublet therapies, triplets improve PFS both in standard-risk and in high-risk patients [57, 61, 72, 125]. Therefore, high-risk patients should preferably be treated with triplet therapy at relapse. Age and comorbidities are also important factors to consider at the time of relapse. Triplets were superior to doublets, also in older patients and in patients with renal dysfunction; however, in these clinical trials frail patients and patients with end-stage renal disease were not included. Therefore, in frail elderly patients, the benefit of triplets is less evident, because they may be more toxic, particularly with regard to hematologic toxicity [27, 126, 127]. More research in this specific patient group is needed.

Daratumumab combinations with lenalidomide-dexamethasone or bortezomib-dexamethasone have shown impressive beneficial HRs for PFS in favor of the triplets, with a HR for PFS of 0.37 and 0.39 , respectively (Tables 3 and 4). Moreover, in these trials the number of patients with MRD negativity was 3.5-5 times higher in patients treated with triplets compared to the doublets. Even some patients with high-risk disease achieved MRD negativity [84]. Therefore, CD38 antibody-based combinations are expected to be first choice in relapsed MM in the near future.

When transplant-eligible MM patients had sufficient benefit from upfront therapy with ASCT ( $>24$ months remission period) or have not been treated with high-dose therapy and ASCT at frontline, then second-line induction therapy followed by high-dose therapy and ASCT is a valuable consolidation strategy [122, 128, 129]. Allogeneic stem-cell transplantation and donor lymphocyte infusion for MM can induce graft-versus-myeloma immunity and long-term survivorship; however, the absence of a consistent OS benefit in comparative studies [130-132] and associated toxicities have prevented its widespread use. Allogeneic stem-cell transplantation may be considered for young patients with high-risk disease at the time of relapse, but preferably in the context of a clinical trial [128, 129].

Treatment recommendations for transplant-eligible and -ineligible patients are schematically depicted in Figs. 2 and 3. 


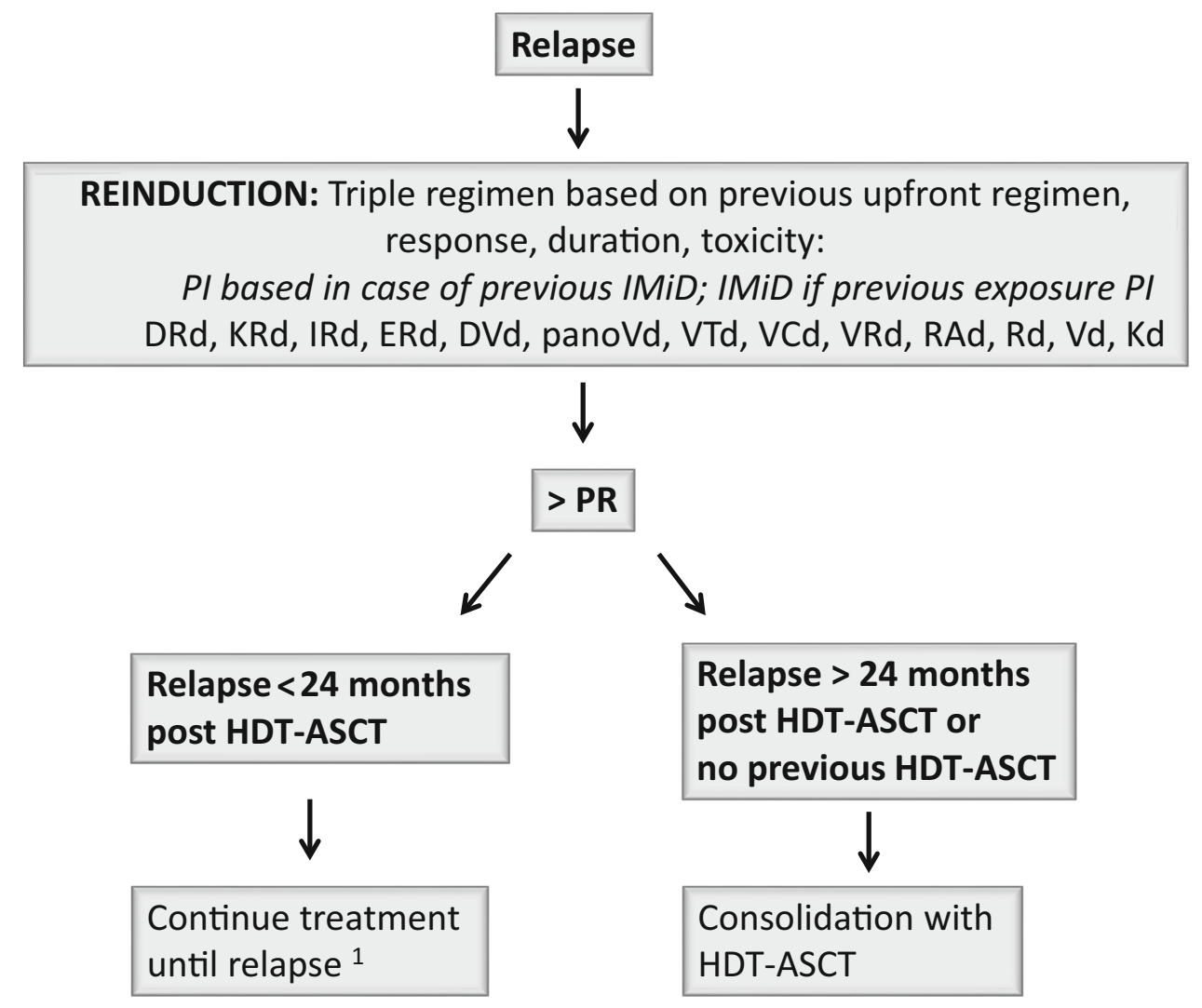

Fig. 2 Treatment recommendations for transplant eligible patients (or young, fitpatients). PI, proteasome inhibitor; IMiD, immunomodulatory drugs; $D R d$, daratumumab-lenalidomide-daratumumab; $K R d$, carfilzomib-lenalidomide-dexamethasone; IRd, ixazomib-lenalidomide-dexamethasone; $E R d$, elotuzumab-lenalidomide-dexamethasone; $D V d$, daratumumab-bortezomib-daratumumab; PanoVd, panobinostat-bortezomib-dexamethasone; $V T d$, bortezomib-thalidomide-dexamethasone; $\quad V C d, \quad$ bortezomib-cyclophosphamide-

\subsection{Treatment Options for Double Refractory, Relapsed and Refractory Multiple Myeloma}

Despite advances in MM therapy during recent years, virtually all myeloma patients eventually relapse. Second and later remissions tend to show shorter durations because of more aggressive tumor behavior at each relapse due to the selection of resistant clones and the development of refractory disease [133]. The prognosis of MM patients who become refractory to the proteasome inhibitor bortezomib and/or carfilzomib and the IMiDs lenalidomide and/ or pomalidomide is especially very poor with an event-free survival and OS of only 5 and 13 months, respectively [8]. This clearly demonstrates that there is an ongoing need for additional active agents and novel treatment approaches with distinct mechanisms of action, especially for this category of MM patients. In the triplet vs doublet studies previously described (Tables 3 and 4), refractory patients dexamethasone; $\quad V R D, \quad$ bortezomib-lenalidomide-dexamethasone; $R a d$, lenalidomide-adriamycine-dexamethasone; $R D$, lenalidomidedexamethasone; $V d$, bortezomib-dexamethasone; $K d$, carfilzomibdexamethasone; $P R$, partial response; HDT-ASCT, high dose therapyautologous stem cell transplantation; allo-SCT, allogeneic stem cell transplantation. 1 Allo-SCT may be considered in young, fit patients; only as part of clinical trial

have not been included and therefore benefit for this particular patient group is not known.

Myeloma patients relapsed or refractory to lenalidomide, bortezomib or both can nowadays be treated with novel generation immunomodulators, or novel generation proteasome inhibitors, or monoclonal antibody therapy. In the relapse setting, retreatment with an agent previously used is considered feasible, provided there was no acquired refractory status, and prior treatment with the regimen produced a clinically meaningful response of adequate duration with acceptable toxicity; in general, the minimal depth of response should be partial response, while the minimal duration of response should be at least 6 months [134]. Another attractive option for the double refractory MM patient is the fully oral three-drug combination of lenalidomide, low-dose cyclophosphamide, and prednisone (REP), which showed an ORR of $67 \%$ in lenalidomiderefractory MM patients (66\% of patients were double- 
Fig. 3 Treatment recommendations for transplant ineligible patients. $P I$, proteasome inhibitor; IMiD, immunomodulatory drugs; dara, daratumumab; $P R$, partial response; $R R M M$, relapsed and/ or refractory multiple myeloma; $R E P$, lenalidomidecyclophosphamideprednisone; $P C d$, pomalidomidecyclophosphamidedexamethasone; $P C P$, pomalidomidecyclophosphamide-prednisone

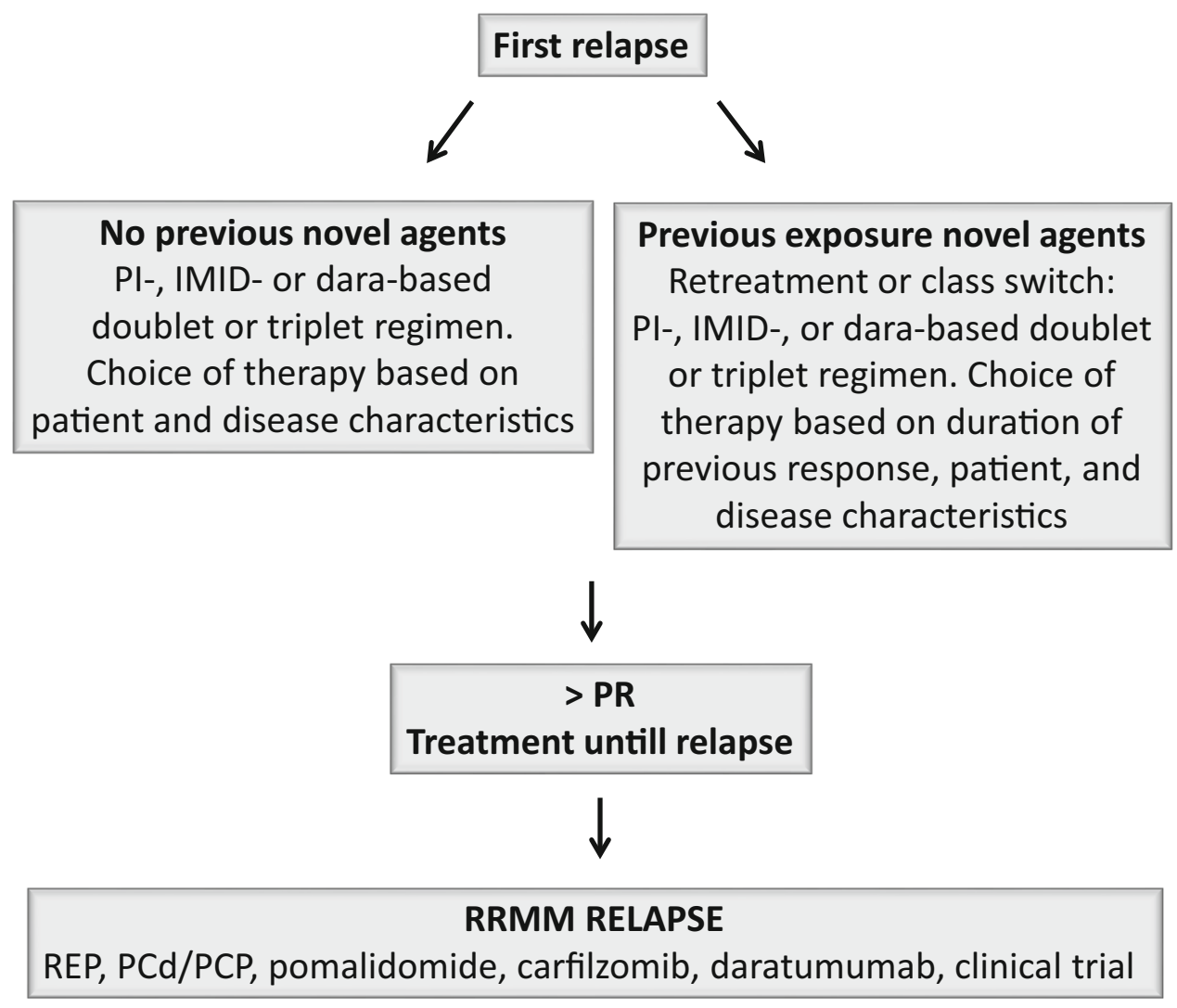

refractory to lenalidomide and bortezomib). Median PFS and OS were 12.1 and 29.0 months, respectively [49]. Importantly, REP therapy consists of a combination of drugs which are generally available in the (outpatient) clinic and is likely associated with lower costs of patient care.

Treatment recommendations for the RRMM setting are depicted in Figs. 2 and 3.

\section{Conclusions}

Advances in the understanding of MM biology as well as the development of novel agents have substantially increased treatment options for RRMM patients over the last decade. Nowadays, choice of relapse treatment in MM is tailored, based on disease and patient characteristics, treatment history, and the needs and goals of the individual patient as summarized in Fig. 1.

Based on higher response rates and prolonged PFS, continuous treatment with three-drug regimens may be preferred for the young, fit and high-risk RRMM patients. In contrast, the goal of treatment for frail elderly relapsed MM patients is to preserve quality of life, which might be pursued by lower-dose intensity regimens with a beneficial toxicity profile. Therefore, sequencing of two-drug therapies instead of three-drug combinations may be preferred in frail patients. Based on the recently obtained encouraging results of CD38 mAb-based combination therapies, it is expected that mAb therapy will become first choice for the treatment of relapsed MM.

Targeted therapies, such as treatment with the BRAF inhibitor vemurafenib in BRAF-mutated MM patients or BCL-2 inhibition with venetoclax for MM with $\mathrm{t}(4 ; 14)$, are currently emerging in RRMM. However, personalized therapy with targeted agents is not yet standard clinical practice. Ongoing innovative randomized and controlled clinical trials are needed to explore and validate predictive biomarkers to guide selection of therapy and to evaluate the efficacy of new promising therapies. Due to the very heterogeneous genetic landscape in MM, the sub-clonality, and the interconnection of signaling pathways, it is expected that combinatorial strategies are needed to achieve durable responses. Rationally designed combination therapies targeting MM cells in the context of their bone marrow micro-environment will induce long-term remissions and might eventually pursue cure of a subset of MM patients by preventing genomic evolution and disease progression. These combinatorial strategies are expected to include monoclonal antibodies, immune checkpoint inhibitors, vaccines, and CAR-T cells as a new treatment paradigm in RRMM in the near future. The final goal 
should be to find a balance among efficacy, toxicity, and cost, and to finally achieve long-lasting control of the disease and eventually even cure in a subset of patients.

\section{Compliance with Ethical Standards}

Funding No funding was received for the preparation of this manuscript. Open Access was funded by the Springer Compact agreement with the Association of Dutch Universities.

Conflicts of interest ISN: no conflicts exist. NvdD: research funding (Janssen, Celgene, Amgen, Novartis and BMS) and advisory board (Janssen, Celgene, Amgen, BMS and Novartis); SZ.: research funding (Janssen, Celgene, Takeda) and advisory board (Takeda, Janssen, Celgene and Novartis); HL: research funding (Genmab, Janssen), and advisory board (Janssen, Takeda, Amgen).

Open Access This article is distributed under the terms of the Creative Commons Attribution-NonCommercial 4.0 International License (http://creativecommons.org/licenses/by-nc/4.0/), which permits any noncommercial use, distribution, and reproduction in any medium, provided you give appropriate credit to the original author(s) and the source, provide a link to the Creative Commons license, and indicate if changes were made.

\section{References}

1. Anderson KC. The 39th David A. Karnofsky lecture: bench-tobedside translation of targeted therapies in multiple myeloma. J Clin Oncol. 2012;30:445-52.

2. Barosi G, Merlini G, Billio A, Boccadoro M, Corradini P, Marchetti M, Massaia M, Tosi P, Palumbo A, Cavo M, Tura S. SIE, SIES, GITMO evidence-based guidelines on novel agents (thalidomide, bortezomib, and lenalidomide) in the treatment of multiple myeloma. Ann Hematol. 2012;91:875-88.

3. Kumar SK, Dimopoulos MA, Kastritis E, et al. Natural history of relapsed myeloma, refractory to immunomodulatory drugs and proteasome inhibitors: a multicenter IMWG study. Leukemia. 2017;31(11):2443-8.

4. Keats JJ, Chesi M, Egan JB, et al. Clonal competition with alternating dominance in multiple myeloma. Blood. 2012;120:1067-76.

5. Bolli N, Avet-Loiseau H, Wedge DC, et al. Heterogeneity of genomic evolution and mutational profiles in multiple myeloma. Nat Commun. 2014;5:2997.

6. Chavan SS, He J, Tytarenko R, et al. Bi-allelic inactivation is more prevalent at relapse in multiple myeloma, identifying RB1 as an independent prognostic marker. Blood Cancer J. 2017;7:e535.

7. Kortuem KM, Braggio E, Bruins L, Barrio S, Shi CS, Zhu YX, Tibes R, Viswanatha D, Votruba P, Ahmann G, Fonseca R, Jedlowski P, Schlam I, Kumar S, Bergsagel PL, Stewart AK. Panel sequencing for clinically oriented variant screening and copy number detection in 142 untreated multiple myeloma patients. Blood Cancer J. 2016;6:e397.

8. Weinhold N, Ashby C, Rasche L, et al. Clonal selection and double-hit events involving tumor suppressor genes underlie relapse in myeloma. Blood. 2016;128:1735-44.

9. Rollig C, Knop S, Bornhauser M. Multiple myeloma. Lancet. 2015;385:2197-208.

10. Mikhael JR, Dingli D, Roy V, et al. Management of newly diagnosed symptomatic multiple myeloma: updated Mayo Stratification of Myeloma and Risk-Adapted Therapy
(mSMART) consensus guidelines 2013. Mayo Clin Proc. 2013;88:360-76.

11. Moreau P, Cavo M, Sonneveld P, et al. Combination of international scoring system 3, high lactate dehydrogenase, and $\mathrm{t}(4 ; 14)$ and/or del(17p) identifies patients with multiple myeloma (MM) treated with front-line autologous stem-cell transplantation at high risk of early MM progression-related death. J Clin Oncol. 2014;32:2173-80.

12. Greipp PR, Kumar S. Plasma cell labeling index. Methods Mol Med. 2005;113:25-35.

13. Gastinne T, LeLeu X, Duhamel A, et al. Plasma cell growth fraction using Ki-67 antigen expression identifies a subgroup of multiple myeloma patients displaying short survival within the ISS stage I. Eur J Haematol. 2007;79:297-304.

14. Palumbo A, Avet-Loiseau H, Oliva S, et al. Revised international staging system for multiple myeloma: a report from International Myeloma Working Group. J Clin Oncol. 2015;33:2863-9.

15. Kuiper R, Broyl A, de Knegt y, van Vliet MH, et al. A gene expression signature for high-risk multiple myeloma. Leukemia. 2012;26:2406-13.

16. Shaughnessy JD Jr, Zhan F, Burington BE, et al. A validated gene expression model of high-risk multiple myeloma is defined by deregulated expression of genes mapping to chromosome 1 . Blood. 2007;109:2276-84.

17. Shaughnessy JD Jr, Qu P, Usmani S, Heuck CJ, Zhang Q, Zhou Y, Tian E, Hanamura I, van Rhee F, Anaissie E, Epstein J, Nair B, Stephens O, Williams R, Waheed S, Alsayed Y, Crowley J, Barlogie B. Pharmacogenomics of bortezomib test-dosing identifies hyperexpression of proteasome genes, especially PSMD4, as novel high-risk feature in myeloma treated with Total Therapy 3. Blood. 2011;118:3512-24.

18. Moreau P, Attal M, Caillot D, et al. prospective evaluation of magnetic resonance imaging and $[18 \mathrm{~F}]$ fluorodeoxyglucose positron emission tomography-computed tomography at diagnosis and before maintenance therapy in symptomatic patients with multiple myeloma included in the IFM/DFCI 2009 Trial: results of the IMAJEM Study. J Clin Oncol. 2017;35:2911-8.

19. Gonsalves WI, Rajkumar SV, Gupta V, et al. Quantification of clonal circulating plasma cells in newly diagnosed multiple myeloma: implications for redefining high-risk myeloma. Leukemia. 2014;28:2060-5.

20. Durie BG, Harousseau JL, Miguel JS, et al. International uniform response criteria for multiple myeloma. Leukemia. 2006;20:1467-73.

21. Kyle RA, Rajkumar SV. Criteria for diagnosis, staging, risk stratification and response assessment of multiple myeloma. Leukemia. 2009;23:3-9.

22. Rajkumar SV, Harousseau JL, Durie B, et al. Consensus recommendations for the uniform reporting of clinical trials: report of the International Myeloma Workshop Consensus Panel 1. Blood. 2011:117:4691-5.

23. Anderson KC, Kyle RA, Rajkumar SV, Stewart AK, Weber D, Richardson P. Clinically relevant end points and new drug approvals for myeloma. Leukemia. 2008;22:231-9.

24. Ludwig H, Sonneveld P, Davies F, et al. European perspective on multiple myeloma treatment strategies in 2014. Oncologist. 2014;19:829-44.

25. Palumbo A, Bringhen S, Mateos MV, et al. Geriatric assessment predicts survival and toxicities in elderly myeloma patients: an International Myeloma Working Group report. Blood. 2015;125:2068-74.

26. Engelhardt M, Dold SM, Ihorst G, Zober A, Moller M, Reinhardt H, Hieke S, Schumacher M, Wasch R. Geriatric assessment in multiple myeloma patients: validation of the International Myeloma Working Group (IMWG) score and 
comparison with other common comorbidity scores. Haematologica. 2016;101:1110-9.

27. Larocca A, Palumbo A. How I treat fragile myeloma patients. Blood. 2015;126:2179-85.

28. Sonneveld P, Broijl A. Treatment of relapsed and refractory multiple myeloma. Haematologica. 2016;101:396-406.

29. van de Donk NW, Lokhorst HM, Dimopoulos M, et al. Treatment of relapsed and refractory multiple myeloma in the era of novel agents. Cancer Treat Rev. 2011;37:266-83.

30. Klippel ZK, Chou J, Towlerton AM, Voong LN, Robbins P, Bensinger WI, Warren EH. Immune escape from NY-ESO-1specific T-cell therapy via loss of heterozygosity in the MHC. Gene Ther. 2014;21:337-42.

31. Racanelli V, Leone P, Frassanito MA, Brunetti C, Perosa F, Ferrone S, Dammacco F. Alterations in the antigen processingpresenting machinery of transformed plasma cells are associated with reduced recognition by $\mathrm{CD} 8+\mathrm{T}$ cells and characterize the progression of MGUS to multiple myeloma. Blood. 2010;115:1185-93.

32. Brown RD, Pope B, Yuen E, Gibson J, Joshua DE. The expression of $\mathrm{T}$ cell related costimulatory molecules in multiple myeloma. Leuk Lymphoma. 1998;31:379-84.

33. Benson DM Jr, Bakan CE, Mishra A, Hofmeister CC, Efebera Y, Becknell B, Baiocchi RA, Zhang J, Yu J, Smith MK, Greenfield CN, Porcu P, Devine SM, Rotem-Yehudar R, Lozanski G, Byrd JC, Caligiuri MA. The PD-1/PD-L1 axis modulates the natural killer cell versus multiple myeloma effect: a therapeutic target for CT-011, a novel monoclonal anti-PD-1 antibody. Blood. 2010;116:2286-94.

34. Liu J, Hamrouni A, Wolowiec D, Coiteux V, Kuliczkowski K, Hetuin D, Saudemont A, Quesnel B. Plasma cells from multiple myeloma patients express B7-H1 (PD-L1) and increase expression after stimulation with IFN-\{gamma $\}$ and TLR ligands via a MyD88-, TRAF6-, and MEK-dependent pathway. Blood. 2007;110:296-304.

35. Paiva B, Azpilikueta A, Puig N, et al. PD-L1/PD-1 presence in the tumor microenvironment and activity of PD-1 blockade in multiple myeloma. Leukemia. 2015;29:2110-3.

36. Tamura H, Ishibashi M, Yamashita T, Tanosaki S, Okuyama N, Kondo A, Hyodo H, Shinya E, Takahashi H, Dong H, Tamada K, Chen L, Dan K, Ogata K. Marrow stromal cells induce B7$\mathrm{H} 1$ expression on myeloma cells, generating aggressive characteristics in multiple myeloma. Leukemia. 2013;27:464-72.

37. Dosani T, Carlsten M, Maric I, Landgren O. The cellular immune system in myelomagenesis: NK cells and T cells in the development of myeloma [corrected] and their uses in immunotherapies. Blood Cancer J. 2015;5:e306.

38. Sze DM, Giesajtis G, Brown RD, Raitakari M, Gibson J, Ho J, Baxter AG, Fazekas de St GB, Basten A, Joshua DE. Clonal cytotoxic $\mathrm{T}$ cells are expanded in myeloma and reside in the CD8(+)CD57(+)CD28(-) compartment. Blood. 2001;98:2817-27.

39. Malek E, de Lima M, Letterio JJ, Kim BG, Finke JH, Driscoll JJ, Giralt SA. Myeloid-derived suppressor cells: The green light for myeloma immune escape. Blood Rev. 2016;30:341-8.

40. Franssen LE, van de Donk NW, Emmelot ME, Roeven MW, Schaap N, Dolstra H, Hobo W, Lokhorst HM, Mutis T. The impact of circulating suppressor cells in multiple myeloma patients on clinical outcome of DLIs. Bone Marrow Transpl. 2015;50:822-8.

41. Giallongo C, Tibullo D, Parrinello NL, La CP, Di RM, Bramanti V, Di RC, Conticello C, Chiarenza A, Palumbo GA, Avola R, Romano A, Di RF. Granulocyte-like myeloid derived suppressor cells (G-MDSC) are increased in multiple myeloma and are driven by dysfunctional mesenchymal stem cells (MSC). Oncotarget. 2016;7:85764-75.
42. Lesokhin AM, Hohl TM, Kitano S, Cortez C, HirschhornCymerman D, Avogadri F, Rizzuto GA, Lazarus JJ, Pamer EG, Houghton AN, Merghoub T, Wolchok JD. Monocytic CCR2(+) myeloid-derived suppressor cells promote immune escape by limiting activated CD8 T-cell infiltration into the tumor microenvironment. Cancer Res. 2012;72:876-86.

43. Quach H, Ritchie D, Stewart AK, Neeson P, Harrison S, Smyth MJ, Prince HM. Mechanism of action of immunomodulatory drugs (IMiDS) in multiple myeloma. Leukemia. 2010;24:22-32.

44. San MJ, Weisel K, Moreau P, et al. Pomalidomide plus low-dose dexamethasone versus high-dose dexamethasone alone for patients with relapsed and refractory multiple myeloma (MM003): a randomised, open-label, phase 3 trial. Lancet Oncol. 2013;14:1055-66.

45. Dimopoulos MA, Palumbo A, Corradini P, et al. Safety and efficacy of pomalidomide plus low-dose dexamethasone in STRATUS (MM-010): a phase 3b study in refractory multiple myeloma. Blood. 2016;128:497-503.

46. LeLeu X, Karlin L, Macro M, et al. Pomalidomide plus lowdose dexamethasone in multiple myeloma with deletion $17 \mathrm{p}$ and/or translocation $(4 ; 14)$ : IFM 2010-02 trial results. Blood. 2015;125:1411-7.

47. Larocca A, Montefusco V, Bringhen S, et al. Pomalidomide, cyclophosphamide, and prednisone for relapsed/refractory multiple myeloma: a multicenter phase 1/2 open-label study. Blood. 2013;122:2799-806.

48. Baz RC, Martin TG III, Lin HY, et al. Randomized multicenter phase 2 study of pomalidomide, cyclophosphamide, and dexamethasone in relapsed refractory myeloma. Blood. 2016;127:2561-8.

49. Nijhof IS, Franssen LE, Levin MD, et al. Phase 1/2 study of lenalidomide combined with low-dose cyclophosphamide and prednisone in lenalidomide-refractory multiple myeloma. Blood. 2016;128:2297-306.

50. Dimopoulos MA, Chen C, Spencer A, Niesvizky R, Attal M, Stadtmauer EA, Petrucci MT, Yu Z, Olesnyckyj M, Zeldis JB, Knight RD, Weber DM. Long-term follow-up on overall survival from the MM-009 and MM-010 phase III trials of lenalidomide plus dexamethasone in patients with relapsed or refractory multiple myeloma. Leukemia. 2009;23:2147-52.

51. Weber DM, Chen C, Niesvizky R, Wang M, Belch A, Stadtmauer EA, Siegel D, Borrello I, Rajkumar SV, Chanan-Khan AA, Lonial S, Yu Z, Patin J, Olesnyckyj M, Zeldis JB, Knight RD. Lenalidomide plus dexamethasone for relapsed multiple myeloma in North America. N Engl J Med. 2007;357:2133-42.

52. Shah JJ, Stadtmauer EA, Abonour R, Cohen AD, Bensinger WI, Gasparetto C, Kaufman JL, Lentzsch S, Vogl DT, Gomes CL, Pascucci N, Smith DD, Orlowski RZ, Durie BG. Carfilzomib, pomalidomide, and dexamethasone for relapsed or refractory myeloma. Blood. 2015;126:2284-90.

53. Siegel DS, Martin T, Wang M, Vij R, Jakubowiak AJ, Lonial S, Trudel S, Kukreti V, Bahlis N, Alsina M, Chanan-Khan A, Buadi F, Reu FJ, Somlo G, Zonder J, Song K, Stewart AK, Stadtmauer E, Kunkel L, Wear S, Wong AF, Orlowski RZ, Jagannath S. A phase 2 study of single-agent carfilzomib (PX171-003-A1) in patients with relapsed and refractory multiple myeloma. Blood. 2012;120:2817-25.

54. Kropff M, Bisping G, Schuck E, Liebisch P, Lang N, Hentrich M, Dechow T, Kroger N, Salwender H, Metzner B, Sezer O, Engelhardt M, Wolf HH, Einsele H, Volpert S, Heinecke A, Berdel WE, Kienast J. Bortezomib in combination with intermediate-dose dexamethasone and continuous low-dose oral cyclophosphamide for relapsed multiple myeloma. $\mathrm{Br} \mathrm{J}$ Haematol. 2007;138:330-7.

55. Schey SA, Morgan GJ, Ramasamy K, Hazel B, Ladon D, Corderoy S, Jenner M, Phekoo K, Boyd K, Davies FE. The addition 
of cyclophosphamide to lenalidomide and dexamethasone in multiply relapsed/refractory myeloma patients; a phase I/II study. Br J Haematol. 2010;150:326-33.

56. Sidra G, Williams CD, Russell NH, Zaman S, Myers B, Byrne JL. Combination chemotherapy with cyclophosphamide, thalidomide and dexamethasone for patients with refractory, newly diagnosed or relapsed myeloma. Haematologica. 2006;91:862-3.

57. Stewart AK, Rajkumar SV, Dimopoulos MA, et al. Carfilzomib, lenalidomide, and dexamethasone for relapsed multiple myeloma. N Engl J Med. 2015;372:142-52.

58. Dimopoulos MA, Moreau P, Palumbo A, et al. Carfilzomib and dexamethasone versus bortezomib and dexamethasone for patients with relapsed or refractory multiple myeloma (ENDEAVOR): a randomised, phase 3, open-label, multicentre study. Lancet Oncol. 2016;17:27-38.

59. Siegel D, Martin T, Nooka A, Harvey RD, Vij R, Niesvizky R, Badros AZ, Jagannath S, McCulloch L, Rajangam K, Lonial S. Integrated safety profile of single-agent carfilzomib: experience from 526 patients enrolled in 4 phase II clinical studies. Haematologica. 2013;98:1753-61.

60. Bringhen S, De WE, Dimopoulos MA. New agents in multiple myeloma: an examination of safety profiles. Clin Lymphoma Myeloma Leuk. 2017;17(7):391-407.

61. Moreau P, Masszi T, Grzasko N, et al. Oral ixazomib, lenalidomide, and dexamethasone for multiple myeloma. $\mathrm{N}$ Engl J Med. 2016;374:1621-34.

62. Badros A, Singh Z, Dhakal B, Kwok Y, MacLaren A, Richardson P, Trikha M, Hari P. Marizomib for central nervous system-multiple myeloma. Br J Haematol. 2017;177:221-5.

63. Mithraprabhu S, Kalff A, Chow A, Khong T, Spencer A. Dysregulated Class I histone deacetylases are indicators of poor prognosis in multiple myeloma. Epigenetics. 2014;9:1511-20.

64. Atadja P. Development of the pan-DAC inhibitor panobinostat (LBH589): successes and challenges. Cancer Lett. 2009;280:233-41.

65. Richardson PG, Mitsiades CS, Laubach JP, Hajek R, Spicka I, Dimopoulos MA, Moreau P, Siegel DS, Jagannath S, Anderson KC. Preclinical data and early clinical experience supporting the use of histone deacetylase inhibitors in multiple myeloma. Leuk Res. 2013;37:829-37.

66. Dimopoulos MA, Siegel DS, Lonial S, et al. Vorinostat or placebo in combination with bortezomib in patients with multiple myeloma (VANTAGE 088): a multicentre, randomised, doubleblind study. Lancet Oncol. 2013;14:1129-40.

67. San-Miguel JF, Hungria VT, Yoon SS, Beksac M, Dimopoulos MA, et al. Panobinostat plus bortezomib and dexamethasone versus placebo plus bortezomib and dexamethasone in patients with relapsed or relapsed and refractory multiple myeloma: a multicentre, randomised, double-blind phase 3 trial. Lancet Oncol. 2014;15:1195-206.

68. White CA, Berlfein JR, Grillo-Lopez AJ. Antibody-targeted immunotherapy for treatment of non-Hodgkin's lymphoma. Curr Pharm Biotechnol. 2000;1:303-12.

69. Sehn LH, Donaldson J, Chhanabhai M, Fitzgerald C, Gill K, Klasa R, MacPherson N, O'Reilly S, Spinelli JJ, Sutherland J, Wilson KS, Gascoyne RD, Connors JM. Introduction of combined CHOP plus rituximab therapy dramatically improved outcome of diffuse large B-cell lymphoma in British Columbia. J Clin Oncol. 2005;23:5027-33.

70. Lonial S, Durie B, Palumbo A, San-Miguel J. Monoclonal antibodies in the treatment of multiple myeloma: current status and future perspectives. Leukemia. 2016;30:526-35.

71. Tai YT, Dillon M, Song W, et al. Anti-CS1 humanized monoclonal antibody HuLuc63 inhibits myeloma cell adhesion and induces antibody-dependent cellular cytotoxicity in the bone marrow milieu. Blood. 2008;112:1329-37.

72. Lonial S, Dimopoulos M, Palumbo A, et al. Elotuzumab therapy for relapsed or refractory multiple myeloma. N Engl J Med. 2015;373:621-31.

73. Malavasi F, Funaro A, Roggero S, Horenstein A, Calosso L, Mehta K. Human CD38: a glycoprotein in search of a function. Immunol Today. 1994;15:95-7.

74. Lin P, Owens R, Tricot G, Wilson CS. Flow cytometric immunophenotypic analysis of 306 cases of multiple myeloma. Am J Clin Pathol. 2004;121:482-8.

75. Deaglio S, Mehta K, Malavasi F. Human CD38: a (r)evolutionary story of enzymes and receptors. Leuk Res. 2001;25:1-12.

76. de Weers M, Tai YT, van der Veer MS, Bakker JM, Vink T, Jacobs DC, Oomen LA, Peipp M, Valerius T, Slootstra JW, Mutis T, Bleeker WK, Anderson KC, Lokhorst HM, van de Winkel JG, Parren PW. Daratumumab, a novel therapeutic human CD38 monoclonal antibody, induces killing of multiple myeloma and other hematological tumors. J Immunol. 2011;186:1840-8.

77. Overdijk MB, Verploegen S, Bögels M, van Egmond M, van Bueren JJL, Mutis T, Groen RW, Breij E, Martens AC, Bleeker WK, Parren PW. Antibody-mediated phagocytosis contributes to the anti-tumor activity of the therapeutic antibody daratumumab in lymphoma and multiple myeloma. MAbs. 2015;7:311-21.

78. van de Donk NW, Janmaat ML, Mutis T, Lammerts van Bueren JJ, Ahmadi T, Sasser AK, Lokhorst HM, Parren PW. Monoclonal antibodies targeting CD38 in hematological malignancies and beyond. Immunol Rev. 2016;270:95-112.

79. Krejcik J, Casneuf T, Nijhof IS, Verbist B, Bald J, Plesner T, Syed K, Liu K, van de Donk NW, Weiss BM, Ahmadi T, Lokhorst HM, Mutis T, Sasser AK. Daratumumab depletes CD38 + immune-regulatory cells, promotes T-cell expansion, and skews T-cell repertoire in multiple myeloma. Blood. 2016;128(3):384-94.

80. Feng X, Zhang L, Acharya C, An G, Wen K, Qiu L, Munshi NC, Tai YT, Anderson KC. Targeting CD38 Suppresses Induction and Function of $\mathrm{T}$ Regulatory Cells to Mitigate Immunosuppression in Multiple Myeloma. Clin Cancer Res. 2017;23(15):4290-300.

81. Usmani SZ, Weiss BM, Plesner T, et al. Clinical efficacy of daratumumab monotherapy in patients with heavily pretreated relapsed or refractory multiple myeloma. Blood. 2016;128:37-44.

82. Dimopoulos MA, Oriol A, Nahi H, et al. Daratumumab, lenalidomide, and dexamethasone for multiple myeloma. N Engl J Med. 2016;375:1319-31.

83. Moreau P, Kaufman JL, Sutherland HJ. Efficacy of daratumumab, lenalidomide and dexamethasone verus lenalidomide and dexamethasone alone for relapsed or refractory multiple myelomaamong patients with 1 to 3 prior lines of therapy based on previoius treatment exposure: updated analysis of pollux. Blood. 2016;128(22):489.

84. Avet-Loiseau H, Casneuf T, Chiu C, et al. Evaluation of minimal residual disease (MRD) in relapsed/refractory multiple myeloma (RRMM) patients treated with daratumumab in combination with lenalidomide plus dexamethasone or bortezomib plus dexamethasone. Blood Abstract. 2016;128(22):246.

85. Mateos MV, Estell J, Barreto W, et al. Efficacy of daratumumab, bortezomib, and dexamethasone versus borteozmib and dexamethasone in relased or refractory myeloma based on prior lines of therapy: updated analysis of castor. Blood. 2016;128(22): 1150 . 
86. Palumbo A, Chanan-Khan A, Weisel K, et al. Daratumumab, bortezomib, and dexamethasone for multiple myeloma. N Engl J Med. 2016;375:754-66.

87. Martin T, Mannis GN, Chari A, et al. Phase 1b study of isatuximab and carfilzomib in relapsed and refratory multiple myeloma. Blood. 2016;128(22):2111.

88. Richardson PG, Mikhael JR, Usmani SZ, et al. Preliminary results from a phase $1 \mathrm{~b}$ study of isatuximab in combination with pomalidomide and dexamethasone in relapsed and refractory multiple myeloma. Blood. 2016;128(22):2123.

89. Raab MS, Chatterjee M, Goldschmidt $\mathrm{H}$, et al. A phase I/IIa study of the CD38 antibody MOR202 alone and in combination with pomalidomide or lenalidomide in patients with relapsed or refractory multiple myeloma. Blood. 2016;128(22):1152.

90. Armand P. Immune checkpoint blockade in hematologic malignancies. Blood. 2015;125:3393-400.

91. Ishida Y, Agata Y, Shibahara K, Honjo T. Induced expression of PD-1, a novel member of the immunoglobulin gene superfamily, upon programmed cell death. EMBO J. 1992;11:3887-95.

92. Kearl TJ, Jing W, Gershan JA, Johnson BD. Programmed death receptor-1/programmed death receptor ligand-1 blockade after transient lymphodepletion to treat myeloma. J Immunol. 2013;190:5620-8.

93. Rosenblatt J, Glotzbecker B, Mills H, et al. PD-1 blockade by CT-011, anti-PD-1 antibody, enhances ex vivo T-cell responses to autologous dendritic cell/myeloma fusion vaccine. J Immunother. 2011;34:409-18.

94. Atanackovic D, Luetkens T, Kroger N. Coinhibitory molecule PD-1 as a potential target for the immunotherapy of multiple myeloma. Leukemia. 2014;28:993-1000.

95. Lesokhin A, Ansell S, Scott E, et al. Preliminary results of a phase I study of nivolumab (BMS-936558) in patients with relapsed or refractory lymphoid malignancies. Blood. 2014;124:291.

96. Badros A, Hyjek E, Ma N, et al. Pembrolizumab, pomalidomide and low dose dexamethasone for relapsed/refractory multiple myeloma. Blood. 2017;130(10):1189-97.

97. San Miguel JF, Mateos MV, Shah J, et al. Pembrolizumab in combination with lenalidomide and low-dose dexamethason for relapsed/refractory multiple myeloa (RRMM): Keynote-023. Blood. 2015;126:505.

98. Bae J, Prabhala R, Voskertchian A, et al. A multiepitope of XBP1, CD138 and CS1 peptides induces myeloma-specific cytotoxic $\mathrm{T}$ lymphocytes in $\mathrm{T}$ cells of smoldering myeloma patients. Leukemia. 2015;29:218-29.

99. Eshhar Z, Waks T, Gross G. The emergence of T-bodies/CAR T cells. Cancer J. 2014;20:123-6.

100. Maus MV, June CH. Zoom zoom: racing CARs for multiple myeloma. Clin Cancer Res. 2013;19:1917-9.

101. Ali SA, Shi V, Maric I, et al. T cells expressing an anti-B-cell maturation antigen chimeric antigen receptor cause remissions of multiple myeloma. Blood. 2016;128:1688-700.

102. Cohen AD, Garfall AL, Stadtmauer EA, et al. B-cell maturation antigen (BCMA)-specific chimeric atigen receptor $\mathrm{T}$ cells (CART-BCMA) for multiple myeloma (MM): initial safety and efficacy form a phase I study. Blood. 2016;128:1147.

103. Hideshima T, Anderson KC. Molecular mechanisms of novel therapeutic approaches for multiple myeloma. Nat Rev Cancer. 2002;2:927-37.

104. Hideshima T, Bergsagel PL, Kuehl WM, Anderson KC. Advances in biology of multiple myeloma: clinical applications. Blood. 2004;104:607-18.

105. Hideshima T, Mitsiades C, Tonon G, Richardson PG, Anderson KC. Understanding multiple myeloma pathogenesis in the bone marrow to identify new therapeutic targets. Nat Rev Cancer. 2007;7:585-98.
106. Andrulis M, Lehners N, Capper D, et al. Targeting the BRAF V600E mutation in multiple myeloma. Cancer Discov. 2013;3:862-9.

107. Yordanova A, Hose D, Neben K, et al. Sorafenib in patients with refractory or recurrent multiple myeloma. Hematol Oncol. 2013;31:197-200.

108. Srkalovic G, Hussein MA, Hoering A, et al. A phase II trial of BAY 43-9006 (sorafenib) (NSC-724772) in patients with relapsing and resistant multiple myeloma: SWOG S0434. Cancer Med. 2014;3:1275-83.

109. Sharman JP, Chmielecki J, Morosini D, et al. Vemurafenib response in 2 patients with posttransplant refractory BRAF V600E-mutated multiple myeloma. Clin Lymphoma Myeloma Leuk. 2014;14:e161-3.

110. Shah JJ, Zonder JA, Cohen AD, et al. The novel KSP inhibitor ARRy-520 is active both with and without low-dose deaxmethasone in patients with multiple myeloma refractory to bortezomib and lenalidomide: results from a phase 2 study. Blood. 2012;120:449.

111. LeLeu X, Eeckhoute J, Jia X, et al. Targeting NF-kappaB in Waldenstrom macroglobulinemia. Blood. 2008;111:5068-77.

112. Delbridge AR, Grabow S, Strasser A, Vaux DL. Thirty years of BCL-2: translating cell death discoveries into novel cancer therapies. Nat Rev Cancer. 2016;16:99-109.

113. Green DR, Walczak H. Apoptosis therapy: driving cancers down the road to ruin. Nat Med. 2013;19:131-3.

114. Scarfo L, Ghia P. Reprogramming cell death: BCL2 family inhibition in hematological malignancies. Immunol Lett. 2013; 155:36-9.

115. Touzeau C, Dousset C, Le GS, et al. The Bcl-2 specific BH3 mimetic ABT-199: a promising targeted therapy for $\mathrm{t}(11 ; 14)$ multiple myeloma. Leukemia. 2014;28:210-2.

116. Kumar S, Kaufman JL, Gasparetto C, et al. Efficacy of venetoclax as targeted therapy for relapsed/refractory $\mathrm{t}(11 ; 14) \mathrm{mul}$ tiple myeloma. Blood 2017. https://doi.org/10.1182/blood-201706-788786

117. Moreau P, Chanan-Khan AA, Roberts AW, et al. Venetoclax combined with bortezomib and dexamethasone for patients with relapsed/refractory multiple myeloma. Blood. 2016;128:975.

118. Tai YT, Landesman Y, Acharya C, et al. CRM1 inhibition induces tumor cell cytotoxicity and impairs osteoclastogenesis in multiple myeloma: molecular mechanisms and therapeutic implications. Leukemia. 2014;28:155-65.

119. Vogl DT, Dingli D, Cornell RF, et al. Selinexor and low dose dexamethasone $(\mathrm{Sd})$ in patients with lenalidomide, pomalidomide, bortezomib, carfilzomib and anti-CD38 Ab refractory multiple myeloma (MM): STORM study. Blood. 2016;128:491.

120. Bahlis N, Kotb R, Sebag M, et al. Selinexor in combination with bortezomib and dexamethasone $(\mathrm{SdB})$ demonstrates significant activity in patients with refractory multiple myeloma (MM) including proteasome-inhibitor refractory patients: results of the phase I STOMP trial. Blood. 2017;128:977.

121. Holstein SA, Richardson PG, Laubach JP, McCarthy PL. Management of relapsed multiple myeloma after autologous stem cell transplant. Biol Blood Marrow Transpl. 2015;21:793-8.

122. Cook G, Ashcroft AJ, Cairns DA, et al. The effect of salvage autologous stem-cell transplantation on overall survival in patients with relapsed multiple myeloma (final results from BSBMT/UKMF Myeloma X Relapse [Intensive]): a randomised, open-label, phase 3 trial. Lancet Haematol. 2016;3:e340-51.

123. Palumbo A, Cavallo F, Gay F, et al. Autologous transplantation and maintenance therapy in multiple myeloma. $\mathrm{N}$ Engl $\mathrm{J}$ Med. 2014;371:895-905. 
124. Dimopoulos MA, Lonial S, White D, et al. Eloquent-2 update: a phase 3, randomized, open-label study of elotuzumab in combination with lenalidomide/dexamethasone in patients with relapsed/refractory multiple myeloma - 3-year safety and efficacy follow-up. Blood 2015;126(23):28.

125. Avet-Loiseau H, Fonseca R, Siegel D, et al. Carfilzomib significantly improves the progression-free survival of high-risk patients in multiple myeloma. Blood. 2016;128:1174-80.

126. Larocca A, Bringhen S, Petrucci MT, et al. A phase 2 study of three low-dose intensity subcutaneous bortezomib regimens in elderly frail patients with untreated multiple myeloma. Leukemia. 2016;30:1320-6.

127. Magarotto V, Bringhen S, Offidani M, et al. Triplet vs doublet lenalidomide-containing regimens for the treatment of elderly patients with newly diagnosed multiple myeloma. Blood. 2016;127:1102-8.

128. Giralt S, Garderet L, Durie B, et al. American Society of Blood and Marrow Transplantation, European Society of Blood and Marrow Transplantation, Blood and Marrow Transplant Clinical Trials Network, and International Myeloma Working Group Consensus Conference on salvage hematopoietic cell transplantation in patients with relapsed multiple myeloma. Biol Blood Marrow Transpl. 2015;21:2039-51.

129. Laubach J, Garderet L, Mahindra A, et al. Management of relapsed multiple myeloma: recommendations of the International Myeloma Working Group. Leukemia. 2016;30:1005-17.
130. Franssen LE, Raymakers RA, Buijs A, et al. Outcome of allogeneic transplantation in newly diagnosed and relapsed/refractory multiple myeloma: long-term follow-up in a single institution. Eur J Haematol. 2016;97:479-88.

131. Krishnan A, Pasquini MC, Logan B, et al. Autologous haemopoietic stem-cell transplantation followed by allogeneic or autologous haemopoietic stem-cell transplantation in patients with multiple myeloma (BMT CTN 0102): a phase 3 biological assignment trial. Lancet Oncol. 2011;12:1195-203.

132. Shah N, Callander N, Ganguly S, et al. Hematopoietic stem cell transplantation for multiple myeloma: guidelines from the American Society for Blood and Marrow Transplantation. Biol Blood Marrow Transpl. 2015;21:1155-66.

133. Magrangeas F, Avet-Loiseau H, Gouraud W, et al. Minor clone provides a reservoir for relapse in multiple myeloma. Leukemia. 2013;27:473-81.

134. Mohty B, El-Cheikh J, Yakoub-Agha I, Avet-Loiseau H, Moreau P, Mohty M. Treatment strategies in relapsed and refractory multiple myeloma: a focus on drug sequencing and 'retreatment' approaches in the era of novel agents. Leukemia. 2012;26:73-85.

135. San-Miguel JF, Hungria VT, Yoon SS, et al. Overall survival of patients with relapsed multiple myeloma treated with panobinostat or placebo plus bortezomib and dexamethasone (the PANORAMA 1 trial): a randomised, placebo-controlled, phase 3 trial. Lancet Haematol. 2016;3:e506-15. 